
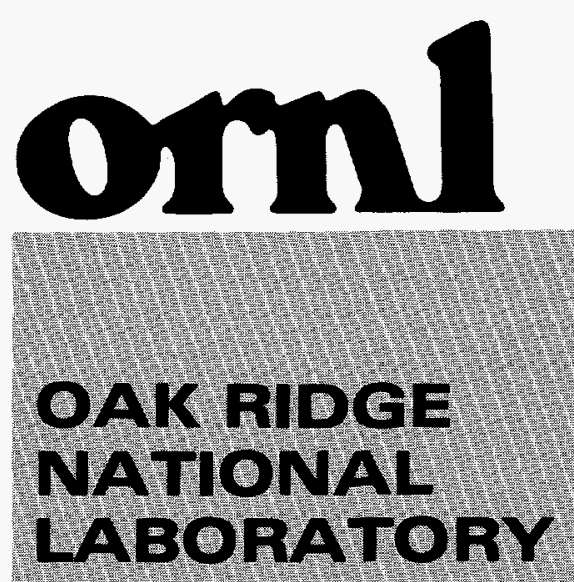

Hag

.
WNAGED AMD OPERATED BY LOCKHEED MARTN ENERGY RESEARCH CORPORMION FoB IHE UTED STATES DEPARTIENT OF ENEROY

\section{RECEIVED \\ OCT 211996 \\ OSTI}

\title{
Ancillary-Service Details: Regulation, Load Following, and Generator Response
}

Eric Hirst

Brendan Kirby

GSTRIBITION OF THS DOCIMENT IS UNLMTED 
This report has been reproduced directly from the best available copy.

Available to DOE and DOE contractors from the Office of Scientific and Technical information, P.O. Box 62, Oak Ridge, TN 37831; prices available from (423) 576-8401, FTS 626-8401.

Available to the public from the National Technical Information Service, U.S. Department of Commerce, 5285 Port Royal Rd., Springfield, VA 22161.

This report was prepared as an account of work sponsored by an agency of the United States Government. Neither the United States Government nor any agency thereof, nor any of their employees, makes any warranty, express or implied, or assumes any legal liability or responsibility for the accuracy, completeness, or usefulness of any information, apparatus, product, or process disclosed, or represents that its use would not infringe privately owned rights. Reference herein to any specific commercial product, process, or service by trade name, trademark, manufacturer, or otherwise, does not necessarily constitute or imply its endorsement, recommendation, or favoring by the United States Government or any agency thereof. The views and opinions of authors expressed herein do not necessarily state or reflect those of the United States Government or any agency thereof. 


\section{DISCLAIMER}

Portions of this document may be illegible in electronic image products. Images are produced from the best available original document. 
ORNL/CON-433

\author{
ENERGY DIVISION
}

\title{
ANCILLARY-SERVICE DETAILS: REGULATION, LOAD FOLLOWING, AND GENERATOR RESPONSE
}

\author{
ERIC HIRST and BRENDAN KIRBY
}

September 1996

Sponsored by

Office of Utility Technologies

Office of Energy Efficiency and Renewable Energy

U.S. Department of Energy

OAK RIDGE NATIONAL LABORATORY

Oak Ridge, Tennessee 37831

managed by

LOCKHEED MARTIN ENERGY RESEARCH CORPORATION

for the

U.S. DEPARTMENT OF ENERGY

under contract No. DE-AC05-96OR22464 



\section{CONTENTS}

Page

SUMMARY $\mathrm{v}$

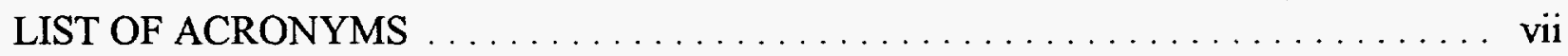

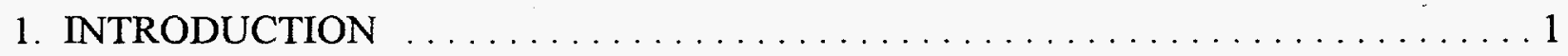

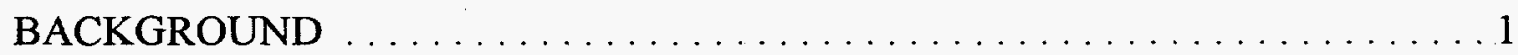

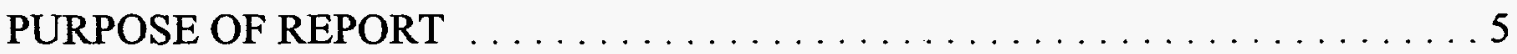

2. COMPARING INTERHOUR AND INTRAHOUR LOAD SWINGS $\ldots \ldots \ldots \ldots \ldots 7$

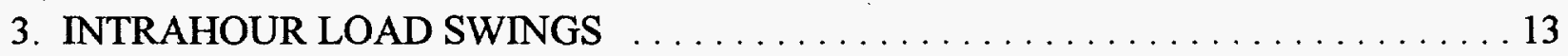

4. AGGREGATE GENERATOR RESPONSE TO LOAD FLUCTUATIONS $\ldots \ldots \ldots 17$

5. GENERATOR-UNIT RESPONSE TO LOAD FLUCTUATIONS $\ldots \ldots \ldots \ldots \ldots 21$

6. EFFECTS OF INDIVIDUAL LOADS ON TOTAL LOAD SWINGS $\ldots \ldots \ldots \ldots 25$

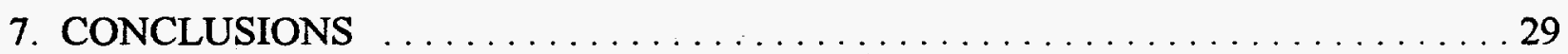

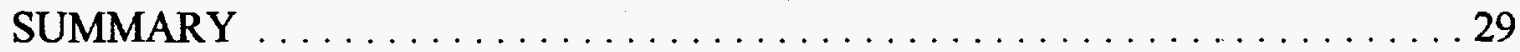

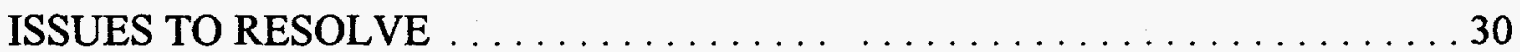

ACKNOWLEDGMENTS . . . . . . . . . . . . . . . . . . . . . . . 31

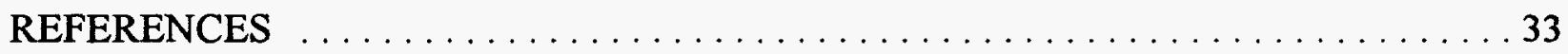



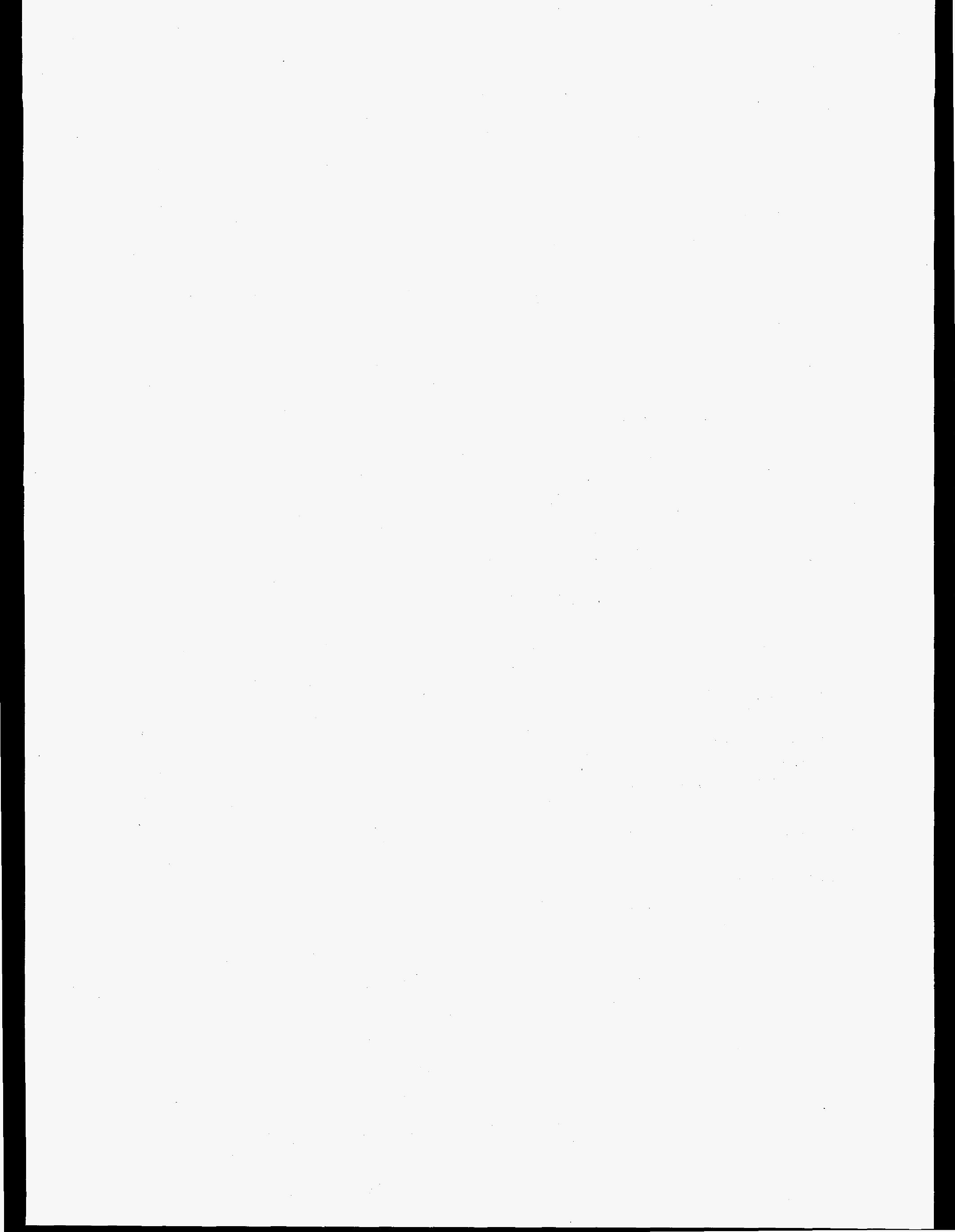


\section{SUMMARY}

Electricity consumption varies with time. These temporal variations include moment-tomoment fluctuations plus hour-to-hour changes associated with diurnal, weekly, and seasonal patterns. Because electricity cannot be easily stored, electric utilities use computers and communications equipment to control their generating units to closely track these time-varying loads. The problem naturally splits into two time frames for both loads and generation: (1) fast fluctuations, on the order of seconds to minutes, and (2) slower fluctuations, on the order of an hour or longer. Fast fluctuations in aggregate load result primarily from the random movements of individual loads. Slower fluctuations result from common external causes, such as time of day, day of the week, and weather.

As long as a single entity (the vertically integrated utility) was responsible for meeting all the requirements to supply loads and maintain reliability, it was only necessary to ensure that sufficient generating capacity of each type was available at all times. With industry restructuring, the introduction of competition, and the unbundling of generation services, it is necessary to quantify both the burdens that individual loads place on the system and the contributions that individual generators make to carrying those burdens. This report develops a framework for determining what burdens are imposed by loads and what contributions are made by generators, based primarily on data from a Midwestern control area.

The Federal Energy Regulatory Commission, in its April 1996 Order 888, required electric utilities to unbundle generation and transmission services. It defined "regulation and frequency response" as the service used to track moment-to-moment fluctuations in system load. It did not discuss the load-following service provided by generators, used to track the interhour variations in load. Figure S-1 decomposes system load into its two components for a three-hour period one winter morning.

This study empirically examines intra- and interhour load following. Because the analysis conducted here is based on very limited data, we suggest further research on these issues. Our initial conclusions are:

- Separating intra- and interhour load fluctuations is straightforward. Although the selection of an appropriate mathematical method to disaggregate loads will depend on the specific data and application, even a simple cubic fit to several hours of data provides a clear distinction between intra- and interhour load dynamics (Fig. S-1).

- Several features define intrahour load fluctuations: the magnitude of load swings (measured in $\mathrm{MW}$ ), the speed of load swings (measured in MW/minute), and the frequency of changes in direction of load swings (increasing vs decreasing loads). 
- Intra- and interhour load following differ in three ways: (1) the magnitude of load swings is much greater for interhour changes, (2) the speed of changes is much greater for intrahour fluctuations, and (3) the frequency of direction changes is much greater for intrahour fluctuations.

- Comparing the dynamics of loads and generation with different time-averaging periods, ranging from 10 seconds to 2 minutes, shows that generation does not follow highfrequency (less than 2-minute) fluctuations. Utilities might be able to reduce the cost of regulation by ignoring the more-rapid load fluctuations. And it may not be appropriate to charge most customers for these high-frequency fluctuations.

- A nontrivial portion of the generating capacity assigned to regulation service contributes to the regulating burden a utility faces. For the particular case examined here, regulating units provided $12 \mathrm{MW} /$ minute, on average, in the primary (correct) direction. At the same time, other regulating units were moving in the wrong direction at $2 \mathrm{MW} /$ minute.

- Regulation is used to track fluctuations in system load, the sum of individual loads. If individual loads are uncorrelated and if the regulation requirement is proportional to the standard deviation of the system load, then regulating costs increase with the square root of system load.

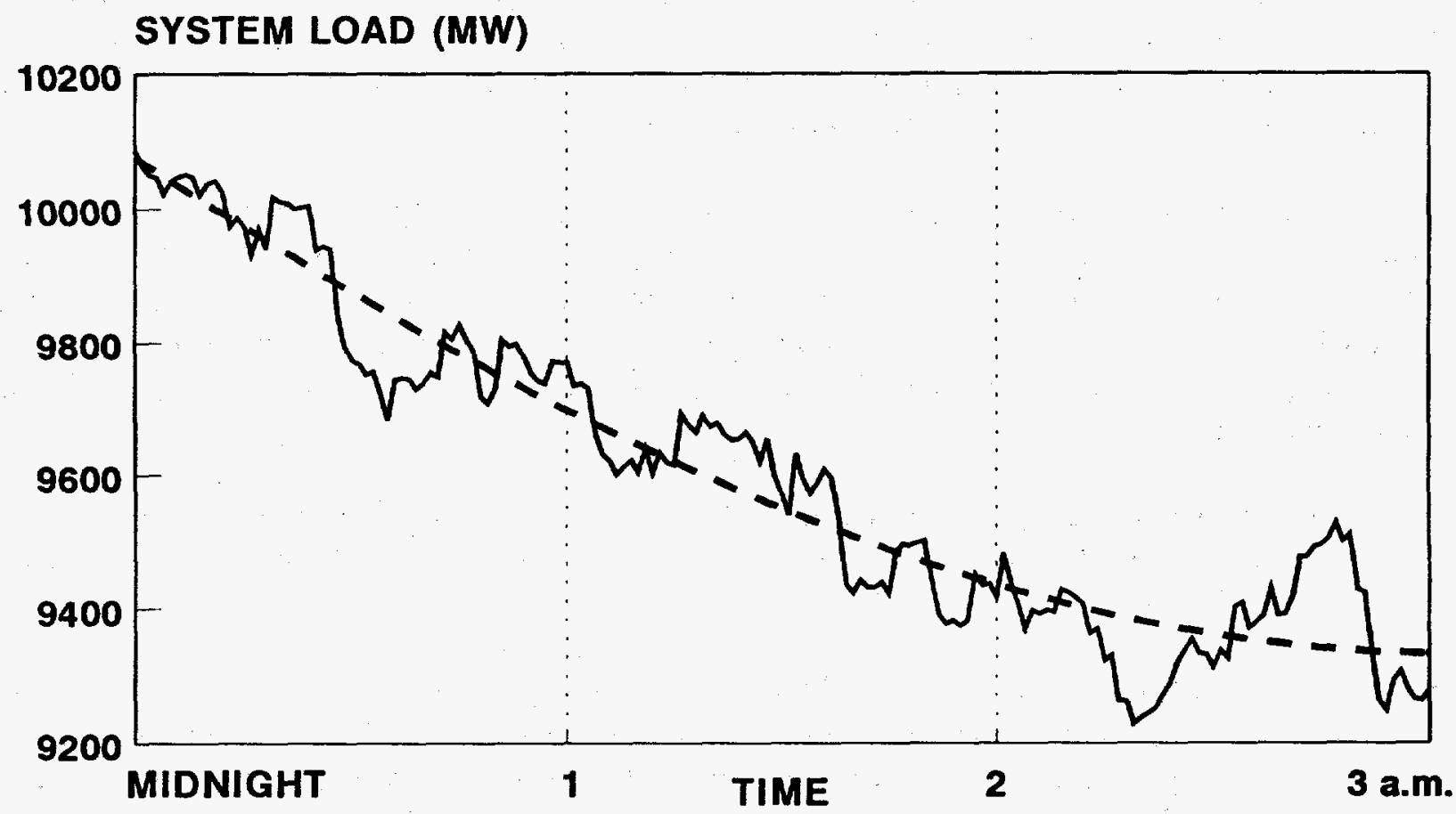

Fig. S-1. System load measured at 1-minute intervals plus a cubic fit to these data for a Midwestern utility, from midnight to 3 a.m. 


\section{LIST OF ACRONYMS}

$\begin{array}{ll}\text { ACE } & \text { Area-control error } \\ \text { AGC } & \text { Automatic generation control } \\ \text { COV } & \text { Coefficient of variation (mean/standard deviation) } \\ \text { FERC } & \text { Federal Energy Regulatory Commission } \\ \text { ISO } & \text { Independent system operator } \\ \text { NERC } & \text { North American Electric Reliability Council } \\ \text { WSCC } & \text { Western Systems Coordinating Council }\end{array}$




\section{INTRODUCTION}

\section{BACKGROUND}

The basic electrical services include generating capacity, energy supply, and power delivery (transmission). Ancillary services are needed to provide the basic electrical services, both to support transactions between buyers and sellers of electricity and to maintain reliability of the interconnected electrical grid. This report examines the concepts and details associated with the function variously called load following, regulation, or regulation and frequency response.

The concept of load following is clear and widely understood; indeed, utilities have been providing this service for decades (1) to match generation to system load and (2) to maintain frequency within the interconnection close to $60 \mathrm{~Hz}$. However, the effort to unbundle generation services shows that the specifics of these services are often ambiguous.

We take an expansive view of this service, as illustrated by Fig. 1. The figure shows the load for a hypothetical customer from 7 a.m. to 8 a.m. on a weekday morning. The total load consists of three primary components. The first element is the minimum constant (base) load during the hour, $80 \mathrm{MW}$ in this example. The second element is the trend during the hour and from hour to hour (the morning pickup in this case); here that element increases monotonically from $0 \mathrm{MW}$ at $7 \mathrm{a} . \mathrm{m}$. to $14 \mathrm{MW}$ at $8 \mathrm{a} . \mathrm{m}$. The third element is the random fluctuations in load around the underlying trend; here the fluctuations range over $\pm 2 \mathrm{MW}$. Combined, the three elements yield a range of loads during this hour of $78 \mathrm{MW}$ to $96 \mathrm{MW}$. This report focuses on the second and third components.

In addition to these three elements, uncertainty about loads further complicates the decision on how to meet load. All three elements are likely to vary from day to day with changes in weather, building occupancy, and other factors unique to the particular customer. For example, a sudden change in wind direction might drive clouds over the service area, in response to which air-conditioning loads would decrease. Data from two utilities in the Southwest show that the day-ahead forecasts of hourly load are off by more than $\pm 2 \%$ of actual load half the time. Control-area operators must have sufficient generation online to respond to such unexpected increases or decreases in load.

The Federal Energy Regulatory Commission (FERC 1996), in its final rule on openaccess transmission, identified six ancillary services that transmission providers must offer to their customers. FERC defines "regulation and frequency response" as the "extra generating capacity, called regulating margin, [required] to follow the moment-to-moment variations in the 
load located in a control area. Following load variations is necessary to maintain scheduled interconnection frequency at sixty cycles per second $(60 \mathrm{~Hz})$."

Regulation and frequency response is the use of generators to help meet the North American Electric Reliability Council (NERC 1992) control-area performance criteria. These criteria require control areas to maintain their area-control error (ACE) within tight limits. ACE, measured in $\mathrm{MW}$, is the instantaneous difference between actual and scheduled interchange plus frequency bias:

$$
A C E=\left(N_{a}-N I_{s}\right)-10 \beta \times\left(F_{a}-F_{s}\right),
$$

where $\mathrm{NI}$ is net interchange, $\beta$ is the frequency bias (measured in $\mathrm{MW} / 0.1 \mathrm{~Hz}$ ), $\mathrm{F}$ is frequency, $a$ is actual, and $s$ is scheduled. The first term in the ACE equation reflects the control area's generation/load balance with the rest of the interconnection, and the second term reflects the interconnection's frequency deviation from the $60-\mathrm{Hz}$ reference (a measure of the interconnection's generation/load balance).

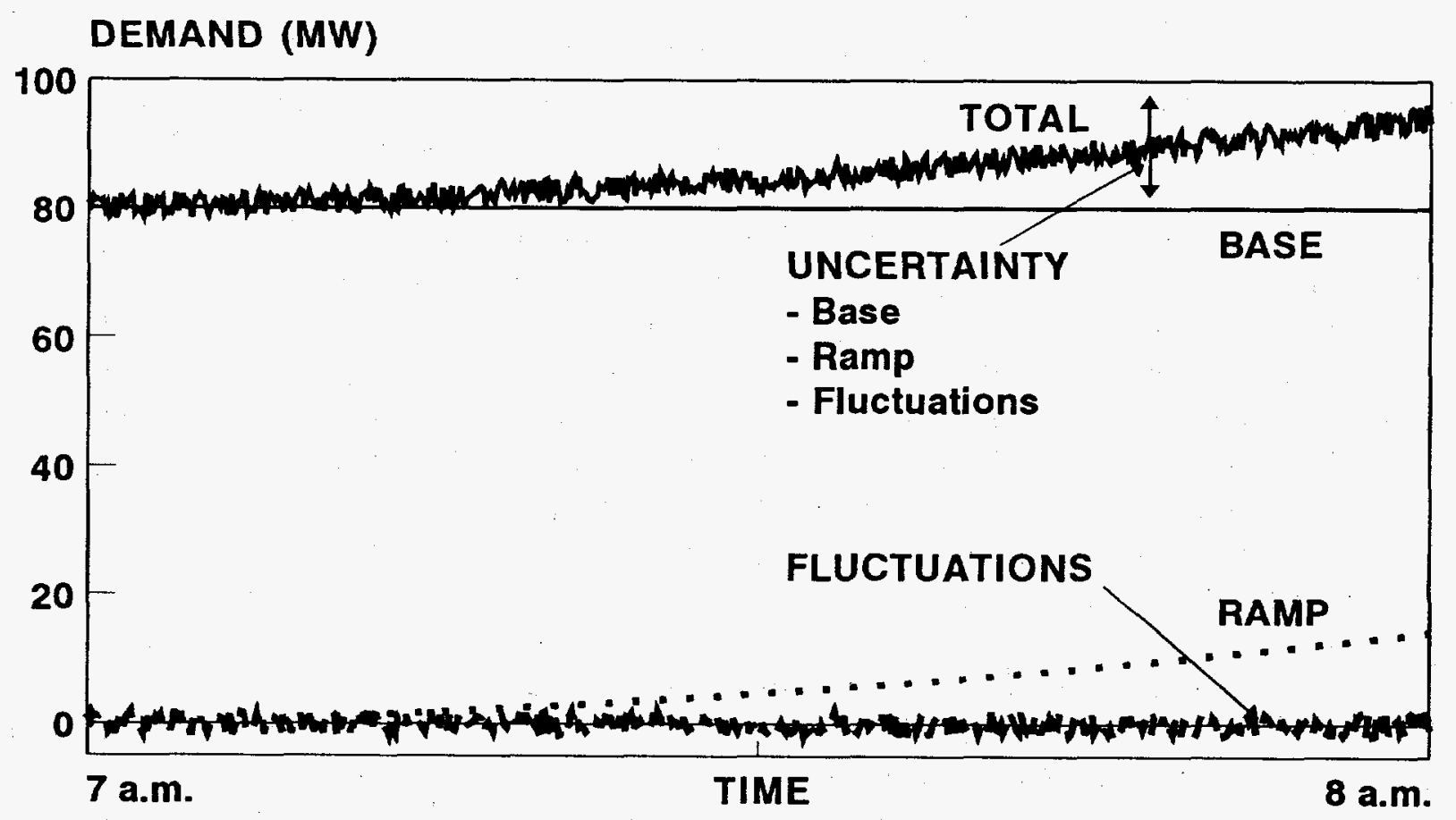

Fig. 1. Components of a hypothetical customer's time-varying load on a weekday morning.

The first of the two control-area performance criteria (called Al) requires that, on an instantaneous-power basis, the control area be in balance with the rest of the interconnection at least once every 10 minutes. The second criterion (A2) requires that the control area's energy imbalance net of frequency bias (average $A C E$ ) be within a certain limit called $L_{d}$ (roughly 0.2 
to $0.5 \%$ of peak demand) every 10 minutes. Utilities deploy automatic-generation-control (AGC) computer systems to manage ACE to meet the A1 and A2 criteria.

In part because of the FERC rulemaking, NERC established an Interconnected Operations Services Working Group to develop an industry consensus on the definitions, requirements, obligations, and management for these services. The NERC working group (1996) identified two services relevant to this study: regulation and load following. Regulation was defined as the generating resources "used to balance supply resources with minute-tominute load variations and to meet NERC control performance criteria" (Sammut 1996). Unlike FERC, the working group separated the generator actions into two parts: (1) those associated with large frequency deviations (to which the generators respond through governor action and then in response to AGC signals) and (2) those associated with the continuous regulation process (in response to AGC signals only). Large frequency deviations are caused by generation or transmission outages and occur rarely. Regulation is required continuously to balance generation and load.

The working group also defined load following as the provision of generation capacity "to meet daily and hourly load variations" (Steitz 1996). This service is intended to follow daily load cycles, in particular the morning pickup and afternoon dropoff that most utility systems experience.

A recent Oak Ridge National Laboratory report (Hirst and Kirby 1996) identified four components of load following. The two control-area functions are maintenance of interconnection frequency at $60 \mathrm{~Hz}$ and maintenance of generation/load balance within the control area. These two functions are identical to what FERC calls "regulation and frequency response." The two customer functions include following the moment-to-moment fluctuations in loads (what the working group calls regulation) and following the longer-term (e.g., interhour) changes in load (what the working group calls load following). The two sets of functions are equivalent to each other. That is, if a control area completely and accurately meets the two customer functions, it will automatically meet its control-area responsibilities.

Neither the FERC nor the NERC nor the Oak Ridge discussions of ancillary services defined the appropriate time period over which to measure "moment-to-moment variations" in load, the speed with which load changes occur, or the amounts and ramp rates of generation needed to provide this service. None of these entities defined the boundaries between intra- and interhour load following, and none developed a suitable mechanism for extracting intrahour load-following patterns from load data.

*This statement is not precisely correct because a control area's contribution to interconnection frequency control is determined by the interconnection's generation/load balance and is independent of the control area's individual performance in meeting its system load. 
The recent filing from the three California investor-owned utilities (Pacific Gas and Electric, San Diego Gas and Electric, and Southern California Edison 1996) on the creation of an independent system operator (ISO) also did not provide details on load following. Specifically, the utilities identified the need for "generating units equipped and operating with automatic generation control, which will enable such units to respond to the ISO's direct digital control signals to match, on a real-time basis, loads and resources consistent with established NERC and WSCC [Western Systems Coordinating Council] operating criteria." But they did not define "real-time basis," nor did they quantify the amounts and speed of generating units needed to provide this service. The proposed restructuring of the PJM Interconnection Association (1996) was similarly vague on load-following services.

Part of the confusion about these services involves the time scales over which they are provided. Generators respond automatically (based on their inertia, governor control, impedance, and electrical proximity to the load) to fluctuations that occur faster than a second or two. Generators respond to slower fluctuations based on signals from the control-area operator's AGC system. The AGC system measures ACE every two to six seconds and sends signals to those generators that provide regulating service to increase or decrease output. Once every several minutes, the AGC system reoptimizes the generation dispatch to minimize operating costs. The control-area operator manually directs individual generators to ramp up and down over the course of an hour or more to track expected interhour load trends.

Thus, generator response to fast (less than a few seconds) fluctuations is automatic, based on the electrical properties of the generators and transmission system. Generator response to load fluctuations on the order of several seconds to several minutes, on the other hand, is managed by the AGC system in its effort to meet the NERC performance criteria. Generator response to longer-term load changes (several minutes to several hours) is based on manual directions and on the economic optimization of the AGC system. We might call the services that generators provide during these three time periods autonomous generator response, regulation, and load following.

In addition to differences in time scale, these load-following services differ according to perspective. The owners and operators of generating units want to know what services they are required to provide, what services they will be allowed to compete to provide, what it will cost them to provide those services, and what they will be paid for those services. System operators want to be sure that they have sufficient resources under their control to meet the NERC performance criteria to maintain system reliability. And customers want to know what services they must purchase, why they must buy them, and how much they must pay for them. Thus, suppliers, ISOs, and customers need to agree on precise definitions of the fast (intrahour) and slow (interhour) load-following services and on the generation resources needed to provide those services. Absent such agreement, the parties will face ongoing controversies about who is providing what to whom and who should pay how much for what services. 


\section{PURPOSE OF REPORT}

The purpose of this report is to examine empirically these intrahour and interhour load changes and the responses of a utility's generating resources to those load changes. We analyze data primarily from one control area, to see how it maintains ACE close to zero in an effort to meet the A1 and A2 criteria. Overall, we estimate that load following costs U.S. electric utilities just over $\$ 1$ billion a year, equivalent to about 0.4 mills $/ \mathrm{kWh}$ (Kirby and Hirst 1996).

We first test alternative ways to identify trends over multihour periods using both regression analysis and rolling averages (i.e., to disaggregate time-varying loads into the two components considered here). We compare the effects of various approaches on the resultant intra- and interhour load variations.

Then, we consider several metrics for intrahour load following (equivalent to FERC's regulation and frequency response):

- the magnitude of load swings, measured in MW (and the corresponding amount of generating capacity that must be available to provide this service);

- the rate of change in load, measured in $\mathrm{MW} /$ minute (and the corresponding ramp rate of generating capacity that provides this service);

- the number of changes in the direction of load swings (with possible implications for increased costs associated with lower efficiencies and higher maintenance costs).

We examine these characteristics of load following for different time-averaging periods (ranging from 10 seconds to a few minutes) and compare the dynamics of loads and loadfollowing generation across these time periods. We examine the minute-to-minute performance of the generators that provide regulation (i.e., that are on AGC), individually and collectively. Finally, we consider the contribution of each load to the total load-following requirements of the control area.

To conduct these analyses, we use data for two days (one in December 1995 and one in June 1996) for a Midwestern control area. This utility has a summer peak demand of about $18,000 \mathrm{MW}$ and an average hourly demand during a year of about $9700 \mathrm{MW}$. Over the course of a year, the hour-to-hour load changes range from about $-1500 \mathrm{MW}$ /hour to $+1500 \mathrm{MW} / \mathrm{hour}$, with an average of the absolute change equal to about $340 \mathrm{MW} /$ hour. (The average of the interhour load changes is, almost by definition, zero over an entire year.) The data we analyze include generation and load, both measured at 10 -second intervals. (Load is calculated as the difference between generation and net interchange out.) 



\section{COMPARING INTERHOUR AND INTRAHOUR LOAD SWINGS}

Although we focus here on the intrahour load and generation response (regulation), we discuss interhour variations because of the close link between the two components of load following. Indeed, total load, by definition, is equal to the sum of the intrahour load fluctuations, the interhour load changes, and the base load (which we assume to remain constant throughout an hour); see Fig. 1. Thus, the method used to define interhour load changes automatically determines the pattern of short-term load fluctuations.

The concept of splitting load and generator response into the components shown in Fig. 1 is straightforward and well known. But the mathematics of doing so are less clear. Clearly distinguishing between intra- and interhour load fluctuations and the generation required to provide these two services will be increasingly important in a restructured electricity industry that features unbundled generation services.

We considered and analyzed several ways to identify the interhour load trends. These methods include the use of rolling averages over 10-, 30-, and 60-minute intervals and the use of linear, quadratic, and cubic regression models, each fit to three hours of data. (Fourier analysis can also be used to identify the frequency components of system load.) Table 1 shows that the rolling-average methods produce far too many sign changes in the interhour trend, compared with the six sign changes that the hourly data show for this day. Even the cubic and quadratic methods overestimate the number of sign changes, but this occurs because of the discontinuities at the end of one 3-hour period and the beginning of the next period. Similarly, the 10-minute average and the linear model overestimate the $6.2 \mathrm{MW} /$ minute actual interhour ramp rate for this day.

Because the interhour load trend defined by the 10-minute rolling-average method follows the dynamics too closely, the intrahour fluctuations defined by this method show relatively little variation, as measured by the absolute value and standard deviation of the fluctuations (right side of Table 1). At the other extreme, the linear fit to three hours of data follows the interhour load trend so poorly that the resultant intrahour fluctuation is greatly exaggerated. The 60-minute rolling average and the cubic fit yield similar definitions for the short-term fluctuations.

The top part of Fig. 2 shows the regression-model results from 6 a.m. to 9 a.m., and the bottom part shows the rolling-average results. Our visual inspection of the data and alternative averaging approaches plus the statistics in Table 1 suggest that a cubic fit to the data or a 60- 
minute rolling average perform well. That is, both methods follow the long-term load variations and do not follow the short-term fluctuations.

Table 1. Comparison of alternative methods to define interhour load trends ${ }^{\mathrm{a}}$

\begin{tabular}{|c|c|c|c|c|}
\hline \multirow[b]{2}{*}{ Method } & \multicolumn{2}{|c|}{ Interhour trend } & \multicolumn{2}{|c|}{ Intrahour fluctuations $^{b}$} \\
\hline & $\begin{array}{c}\text { Average of absolute } \\
\text { values of ramp rate } \\
\text { (MW/minute) }\end{array}$ & $\begin{array}{l}\text { Sign changes } \\
\text { per day }\end{array}$ & $\begin{array}{c}\text { Average of } \\
\text { absolute } \\
\text { values }(\mathrm{MW})\end{array}$ & $\begin{array}{c}\text { Standard } \\
\text { deviation } \\
\text { (MW) }\end{array}$ \\
\hline \multicolumn{5}{|c|}{ Rolling average } \\
\hline 10-minute & 9.7 & 159 & 27 & 21 \\
\hline 30-minute & 7.1 & 86 & 47 & 38 \\
\hline 60-minute & 6.4 & 54 & 64 & 52 \\
\hline \multicolumn{5}{|c|}{ Regression model } \\
\hline Cubic & 7.2 & 16 & 61 & 48 \\
\hline Quadratic & 7.8 & 12 & 90 & 67 \\
\hline Linear & 8.3 & 6 & 132 & 101 \\
\hline
\end{tabular}

${ }^{\mathrm{a}}$ These results are based on 1440 1-minute observations for a 24 -hour period in December 1995, with separate fits to the eight 3-hour periods from midnight to midnight.

${ }^{b}$ All six fits to the data resulted in sign changes for the intrahour fluctuations of 29 to 32 times/hour and averages of the absolute value of ramp rates of 19 to $22 \mathrm{MW} / \mathrm{minute}$.

For example, the standard deviation of the short-term fluctuations is $61 \mathrm{MW}$ relative to the cubic fit but $132 \mathrm{MW}$ relative to the linear fit. The intrahour load fluctuations are much higher relative to the linear fit because the linear fit poorly approximates the actual interhour load trend. And the standard deviation is $64 \mathrm{MW}$ relative to the 60 -minute rolling average, but only $27 \mathrm{MW}$ relative to the 10-minute average. The intrahour load fluctuations are much smaller relative to the 10-minute average because averaging for such short time periods leads to an interhour trend that follows much of the intrahour dynamics.

Table 2 compares the characteristics of inter- and intrahour load following. The intrahour results are based on 1-minute averages for this Midwestern utility for a single day in December 1995 (1440 observations in all), calculated as the deviations from cubic fits to the load data. Two sets of interhour results are shown, one for the same day ( 24 hourly observations) as that used to calculate intrahour load results and one for the entire year ( 8760 observations). 
SYSTEM LOAD (MW)

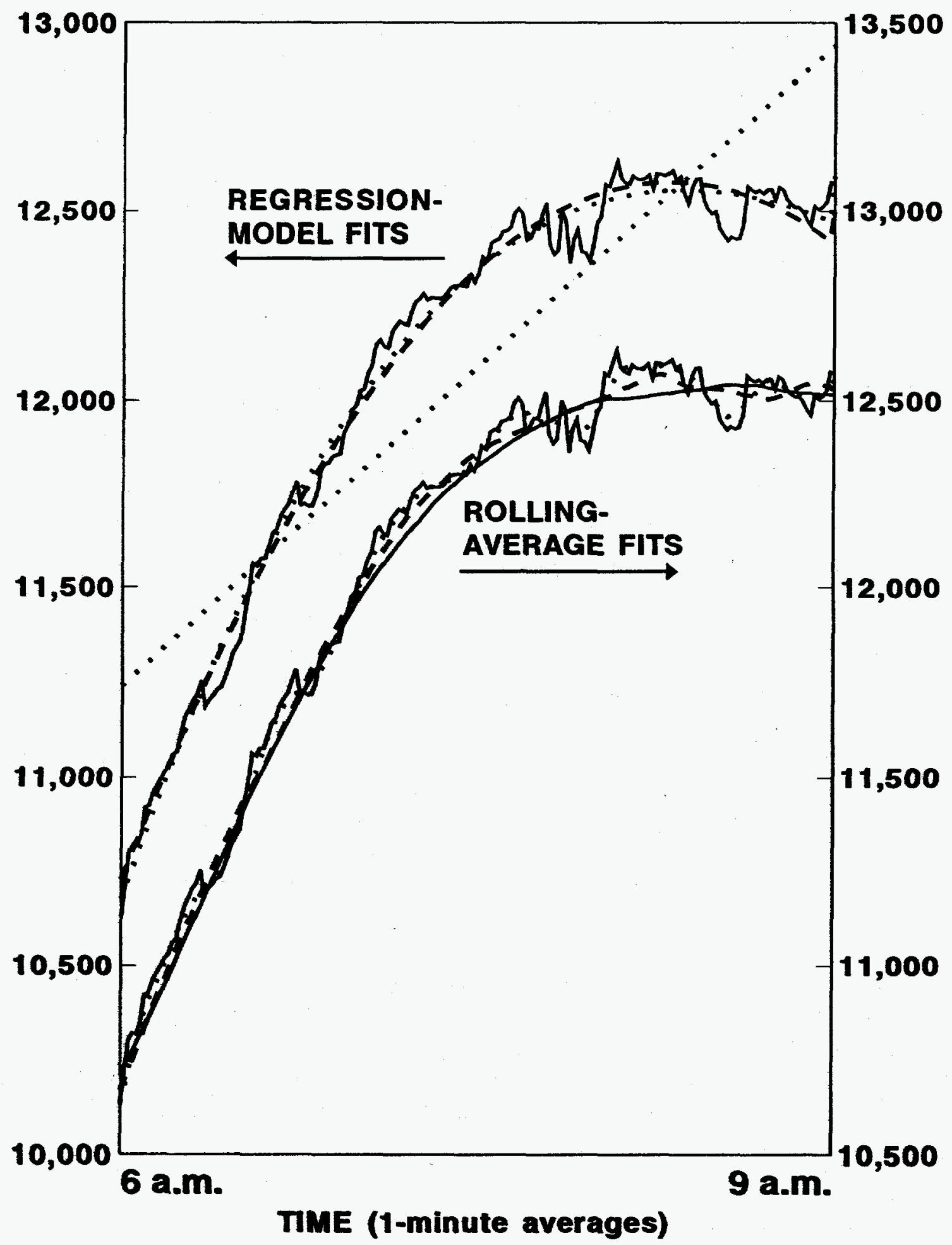

Fig. 2. One-minute loads and several regression-model (top) and rolling-average (bottom) fits to the data from 6 to 9 a.m. for a winter day. 
Table 2. Comparison of intra- and interhour load following

\begin{tabular}{|c|c|c|c|}
\hline & \multirow{2}{*}{$\begin{array}{c}\text { Intrahour } \\
\text { 24-hour } \\
\text { day }^{\mathrm{a}}\end{array}$} & \multicolumn{2}{|c|}{ Interhour } \\
\hline & & 24-hour day ${ }^{\mathrm{a}}$ & 8760 -hour year ${ }^{b}$ \\
\hline \multicolumn{4}{|l|}{ Magnitude of swings (MW) } \\
\hline Maximum & \pm 170 & $\pm 2,100$ & $\pm 6,000$ \\
\hline Average & $0\left(48^{\mathrm{c}}\right)$ & 11,700 & 9,700 \\
\hline Standard deviation & 61 & 1,400 & 2,000 \\
\hline \multicolumn{4}{|l|}{ Rate of change (MW/minute) } \\
\hline Maximum & \pm 125 & \pm 20 & \pm 26 \\
\hline Average of absolute values ${ }^{c}$ & 20 & 6.2 & 5.7 \\
\hline Number of sign changes per hour & 31 & 0.27 & 0.19 \\
\hline
\end{tabular}

${ }^{2}$ These results are for a single day in December 1995. The intrahour results are based on 1 -minute averages. The interhour results are based on hourly averages.

${ }^{b_{T}}$ These results are for the entire year 1994.

The average of the intrahour load swings is, by definition, zero.

Over the course of a year, loads range from a low of $5900 \mathrm{MW}$ (early morning hours during the spring and fall) to almost $18,000 \mathrm{MW}$ (summer afternoon hours). The hourly load changes reach more than $1500 \mathrm{MW} /$ hour, with the increases typically occurring between 6 and 7 a.m. and the decreases occurring in the summer between 11 p.m. and midnight (Fig. 3).

Aggregate intra- and interhour load following differ in three important ways:

- The magnitude (in MW) of load swings is much greater for interhour changes than for intrahour changes; the difference is a factor of 15 to 40 .

- The speed of changes (MW/minute) is much greater for intrahour changes than for interhour changes; the difference is a factor of 3 to $5^{*}$

- The frequency of change in direction (i.e., the sign on the ramp rate) is much greater for intrahour changes than for interhour changes; the difference is roughly a factor of 100 .

*We measure the speed of load fluctuations by comparing load at one instant to load at the prior instant $\left(L_{t}-L_{t-1}\right)$, which is essentially the first derivative of load. We measure load fluctuations by comparing instantaneous load to the load trend $\left(\mathrm{L}_{\mathrm{t}}-\mathrm{L}_{\text {trend }}\right)$. 
These differences in the amount and speed of load changes affect the types of generating units needed to respond to these two kinds of load changes. Generators used to provide regulating service must respond quickly to frequent, but small, load changes. On the other hand, generators used to provide load-following service must respond to large, but slowly changing, loads.

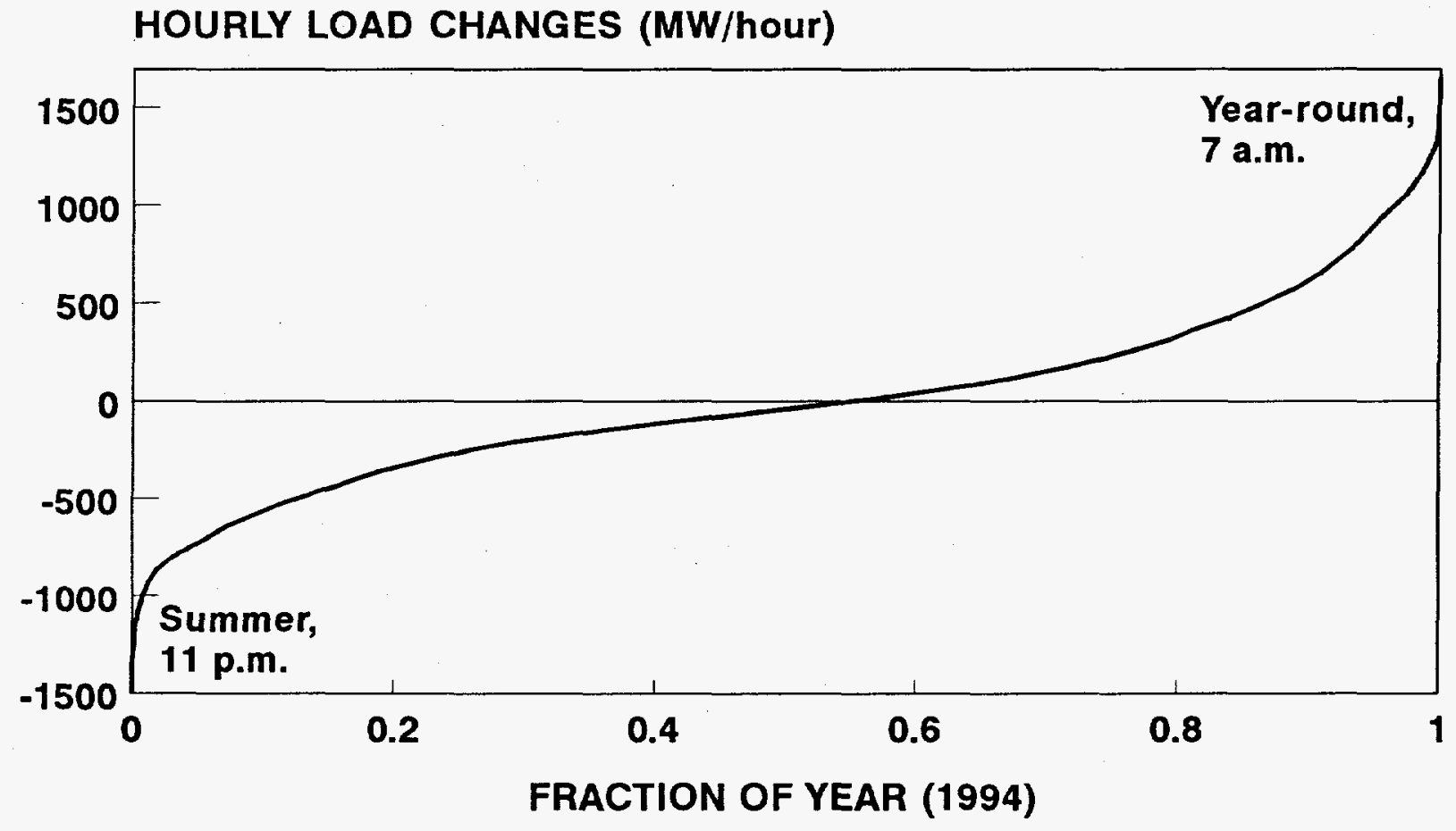

Fig. 3. Distribution of hourly load swings for 1994. 



\section{INTRAHOUR LOAD SWINGS}

As Fig. 4 shows, overall load declined from 10,100 MW at midnight to about $9300 \mathrm{MW}$ at 3 a.m., an $8 \%(800-\mathrm{MW})$ drop, based on a cubic fit to these data. ${ }^{*}$ The 1 -minute load data fluctuate around this trendline with a maximum 1-minute change of $170 \mathrm{MW}$ in either direction and a standard deviation of $67 \mathrm{MW}$. Ignoring the direction of change, loads fluctuate an average of $55 \mathrm{MW}$ at an average rate of $21 \mathrm{MW} /$ minute during this 3-hour period. The load fluctuations change sign (e.g, from increasing to decreasing) $54 \%$ of the time; in other words, roughly once every other minute loads change from decreasing to increasing or from increasing to decreasing.

Figure 5 shows the 10-second "speeds" for load and generation (discussed in Chapter 4) from midnight to 1 a.m. Loads move up or down at an average rate of $74 \mathrm{MW} / \mathrm{minute}$ and change direction more than 200 times per hour.

Table 3 shows how the range, average, and standard deviation of the load fluctuations and their speeds change when the time-averaging period is increased from 10 seconds to 2 minutes. While the measures of magnitude drop by 4 to $15 \%$ in going from the 10 -second to the 2-minute level, the measures of rate-of-change drop dramatically, by 80 to $95 \%$. Thus, the standard deviation and average for the magnitude of load swings are nearly independent of the time-averaging period used to define intrahour load swings. (We know of two utilities that observed near-constant standard deviations in their analyses of intrahour load fluctuations.) However, the rate-of-change measures are strongly dependent on the averaging period; the longer the averaging period, the slower the rate of change and the fewer the direction changes.

"The least-squares fit to these 1-minute data is:

$$
\text { Load }(M W)=10,068-(5.823 \times t)-\left(0.00864 \times t^{2}\right)+\left(0.000107 \times t^{3}\right) \text {, }
$$

where $t$ is time measured in 1 -minute intervals beginning at midnight $(t=1)$ and ending at 3 a.m. $(t=181)$. The $R^{2}$ for this model is 0.92 , and all four coefficients are statistically significant at the $2 \%$ level or better, except for the $t^{2}$ coefficient, which is not significant at all.

"Had we calculated the intrahour load fluctuations relative to a linear fit to the data for this three-hour period, the statistics on load swings (MW) would have been about $25 \%$ higher. But the statistics on ramp rates (MW/minute) and frequency of direction changes would have been very close to the results presented above, based on fluctuations relative to a cubic fit to the data. 


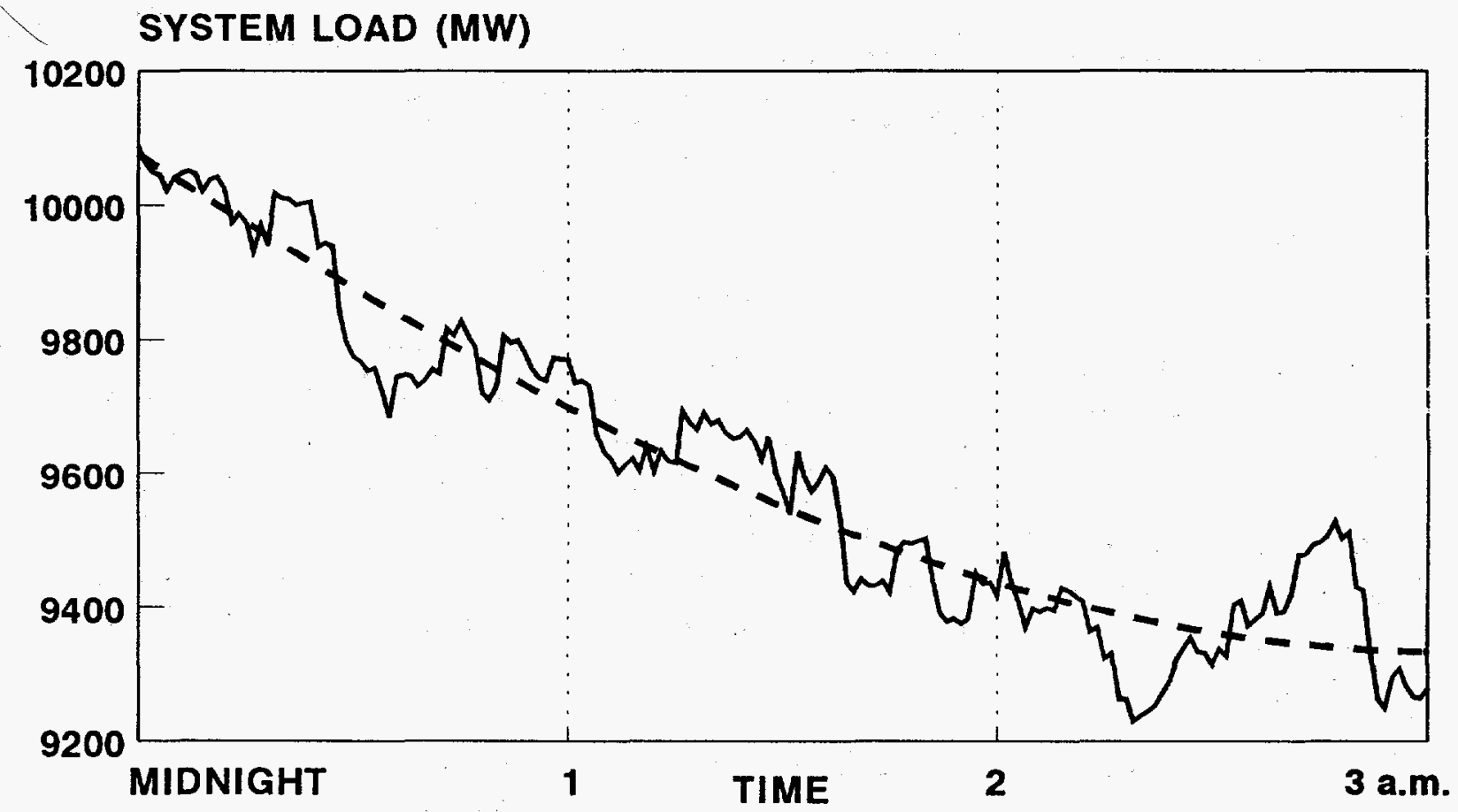

Fig. 4. Total load measured every minute for a Midwestern utility and a cubic fit to the data, from midnight to 3 a.m.

10-SECOND FLUCTUATIONS (MW/minute)

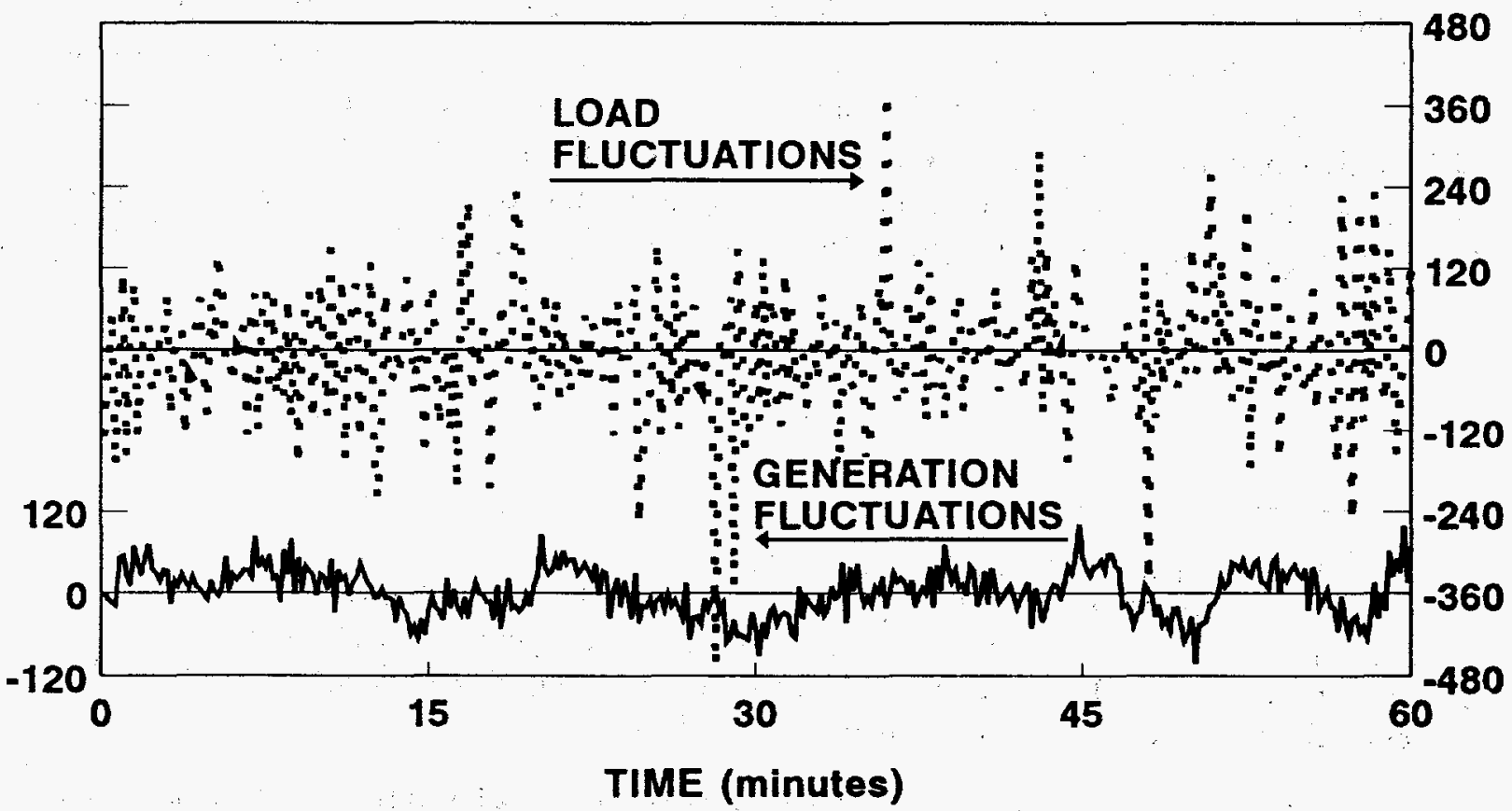

Fig. 5. Fluctuations in system load and total generation (measured at 10-second intervals) from midnight to 1 a.m. 
Table 3. Effects on intrahour load swings from midnight to 3 a.m. of increasing the time over which load is averaged

\begin{tabular}{lcccccc}
\hline $\begin{array}{l}\text { Averaging } \\
\text { period } \\
\text { (seconds) }\end{array}$ & \multicolumn{2}{c}{ Magnitude of swings (MW) } & & \multicolumn{2}{c}{ Rate of change (MW/minute) } \\
\cline { 2 - 3 } & Maximum & $\begin{array}{c}\text { Average of } \\
\text { absolute values }\end{array}$ & $\begin{array}{c}\text { Standard } \\
\text { deviation }\end{array}$ & & $\begin{array}{c}\text { Average of } \\
\text { absolute values }\end{array}$ & $\begin{array}{c}\text { Sign changes } \\
\text { per hour }\end{array}$ \\
\hline 10 & \pm 186 & 57 & 69 & 74 & 205 \\
30 & \pm 178 & 56 & 68 & 31 & 55 \\
60 & \pm 166 & 55 & 67 & 21 & 31 \\
90 & \pm 160 & 54 & 66 & 17 & 14 \\
120 & \pm 155 & 53 & 66 & & 15 & 11 \\
\hline
\end{tabular}

An increase in generator/load imbalance of about $60 \mathrm{MW}$ (the difference in magnitude between the maximum swings at 10 -second vs 120 -second intervals) would increase the frequency deviation in the Eastern Interconnection by only $0.0015 \mathrm{~Hz}$. Even in the Western Interconnection or the Electric Reliability Council of Texas, a 60-MW generator/load imbalance would affect frequency by 0.004 or $0.01 \mathrm{~Hz}$, respectively. [The frequency-response characteristic is $4000 \mathrm{MW} / 0.1 \mathrm{~Hz}$ in the Eastern Interconnection, $1500 \mathrm{MW} / 0.1 \mathrm{~Hz}$ in the Western Interconnection, and $625 \mathrm{MW} / 0.1 \mathrm{~Hz}$ in the Electric Reliability Council of Texas (Benjamin 1996).] The very small frequency deviations associated with a decision to ignore 10second fluctuations and the likelihood that 10 -second load fluctuations across utilities are uncorrelated suggests that control-area operators could safely ignore these high-frequency fluctuations. 



\section{AGGREGATE GENERATOR RESPONSE TO LOAD FLUCTUATIONS}

Figure 5 illustrates the differences in the dynamics of loads and generation. In addition to the 10-second load fluctuations discussed above, this figure shows the 10-second fluctuations in total generation for this control area. Clearly, generation varies much less than does load. Specifically, the average 10 -second load fluctuation is $12.3 \mathrm{MW}$, and the average generation fluctuation is two-thirds less, 4.2 MW. While load reverses direction $56 \%$ of the time, generation reverses direction only $35 \%$ of the time.

One cannot tell from these data whether generation responds slowly to load changes because the generating units are unable to respond more quickly or because control systems do not request faster response. We suspect the latter, because utility AGC systems typically filter the raw ACE signal to avoid having generators move up and down unnecessarily. As noted by Jaleeli et al. (1992), AGC strategies seek to "avoid unnecessary rapid maneuvering of unit generation (or the chasing of high frequency components of demand change)." More broadly, advanced AGC systems can reduce generator movement by both filtering historical ACE signals and by forecasting future loads for the next several minutes (Fink and Erkmen 1987).

These short-term ( 10 -second) mismatches between generation and load are made up by the rest of the Eastern Interconnection. That is, for brief periods, this control area first leans on the interconnection (i.e., it undergenerates) and then other control areas lean on it (i.e., it overgenerates). These presumably uncorrelated discrepancies, which disappear with the longer time-averaging periods discussed below, are equivalent to short-term inadvertent interchanges.

This control area assigns about $150 \mathrm{MW}$ to regulation, equivalent to 2.3 times the standard deviation of load fluctuations (Table 3). ${ }^{*}$ In principle, the control area could assign more generating capacity to load following and assign capacity that has greater ramping capability to reduce these short-term mismatches.

Figure 6 shows that when the time interval for averaging loads and generation is increased from 10 seconds to 1 minute, the load and generation patterns look quite similar. By similar, we include both the amplitude of fluctuations and the frequency with which direction

*This is actually $\pm 150 \mathrm{MW}$ or $300 \mathrm{MW}$ of total range. Following upswings in load requires additional capacity and therefore additional capital costs as well as additional fuel and maintenance costs. Following downswings in load requires suboptimal dispatch of generation, which involves only additional operating and maintenance costs. 
changes. Even at the 1-minute interval, however, generation moves more slowly than does system load. Specifically, the standard deviation of the generation ramp rate is $23 \mathrm{MW} / \mathrm{minute}$, compared with $30 \mathrm{MW} / \mathrm{minute}$ for system load. And generation fluctuations reverse direction $19 \%$ of the time, compared with $49 \%$ for loads. The results shown in Fig. 6 suggest that the generator response to load changes at the 1-minute level is both damped and delayed.

To explore the appropriate time interval more fully, we compared the standard deviation of load fluctuations with that for generation fluctuations for several time-averaging intervals, ranging from 10 seconds to 2 minutes (Fig. 7). Only when the averaging interval reaches 1.5 minutes do the two curves meet. This result suggests that generators either cannot or do not follow load fluctuations at the 10-second level. Rather, generation follows load at roughly the 1.5-minute level. This time interval is roughly consistent with the statement that the "... velocity limits of the generators will not allow control response to load components with a period in the order of 2 minutes or less" (Douglas, Green, and Kramer 1994).

We also examined the correlation coefficient between load and generation fluctuations for different time lags between generation and load. Consistent with the results presented above, the correlation coefficient reached its maximum at two minutes. In other words, generation appears to follow 10 -second or 30-second fluctuations in loads with a two-minute delay.

One utility calculated the amount of generation it assigns to regulation on the basis of the requirement to meet the Al criterion at least $90 \%$ of the time. Its analysis of raw and filtered ACE showed that its regulating units respond at a rate of 18 to $25 \mathrm{MW} /$ minute to meet A1 $90 \%$ of the time. Multiplying 22.5-MW/minute (an average rate) by 10 minutes yields a total capacity of $225 \mathrm{MW}$ assigned to regulation, about $2 \%$ of peak load.

Pacific Gas and Electric (1996), on the other hand, split its load-following requirement into two parts: micro-load following (a few seconds to 10 minutes) and macro-load following (10 minutes to several days). It calculated a total load-following requirement of $0.74 \%$ (123 $\mathrm{MW}$ ) of peak demand. Of this total, $0.25 \%$ (42 MW) was needed for micro-load following. The order-of-magnitude difference between the two utility estimates of regulating requirements ( $2 \%$ vs $0.25 \%$ ) may occur because of differences in how the utilities characterize the short-term load fluctuations (regulation) and the longer-term changes in load. Differences in load characteristics (e.g., volatile loads, such as steel mills), generator characteristics (i.e., MW/minute capabilities), and system size may also contribute to this difference in regulating requirement. 


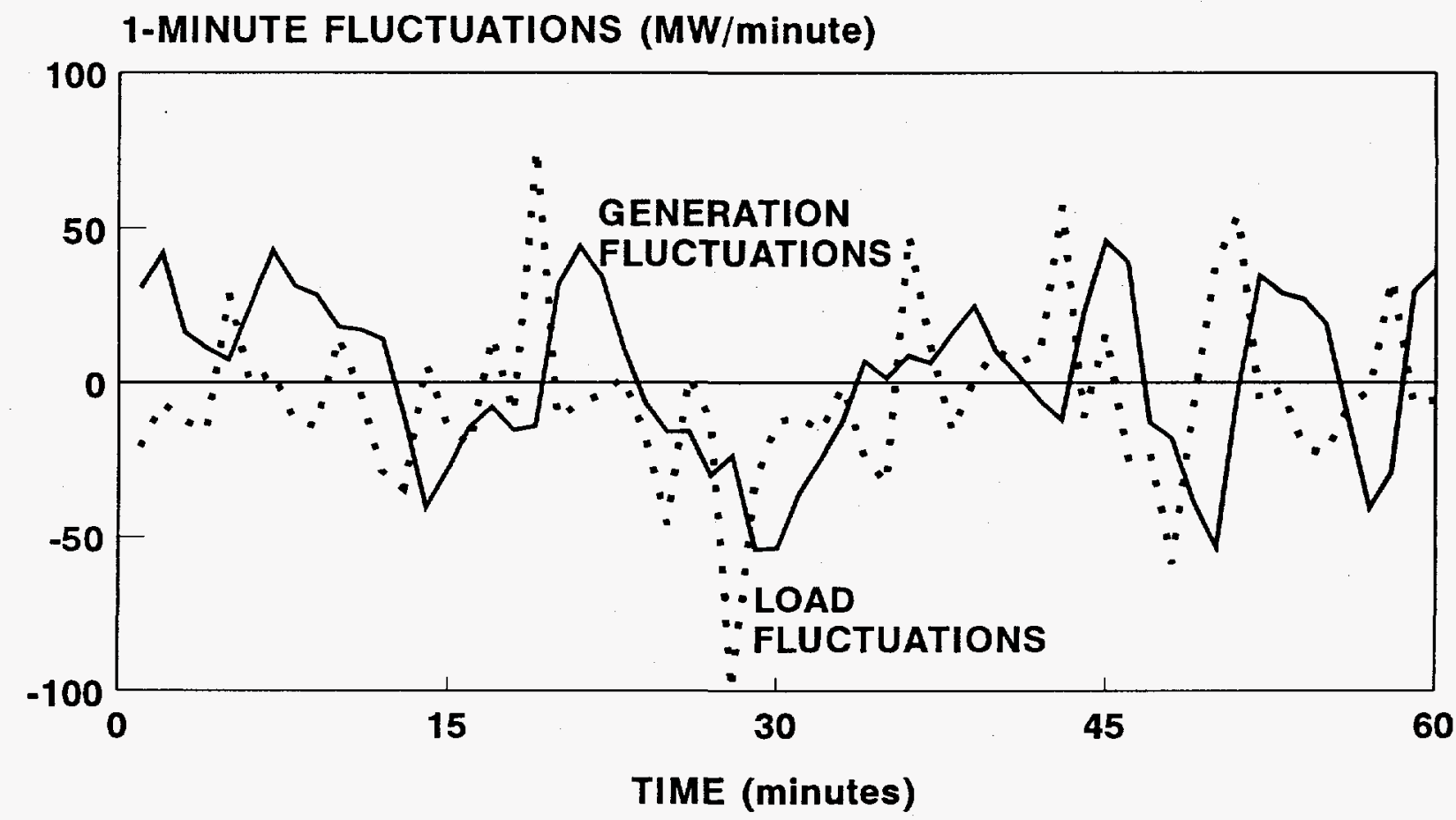

Fig. 6. Fluctuations in system load and total generation (measured at 1-minute intervals) from midnight to 1 a.m. Compare Figs. 5 and 6.

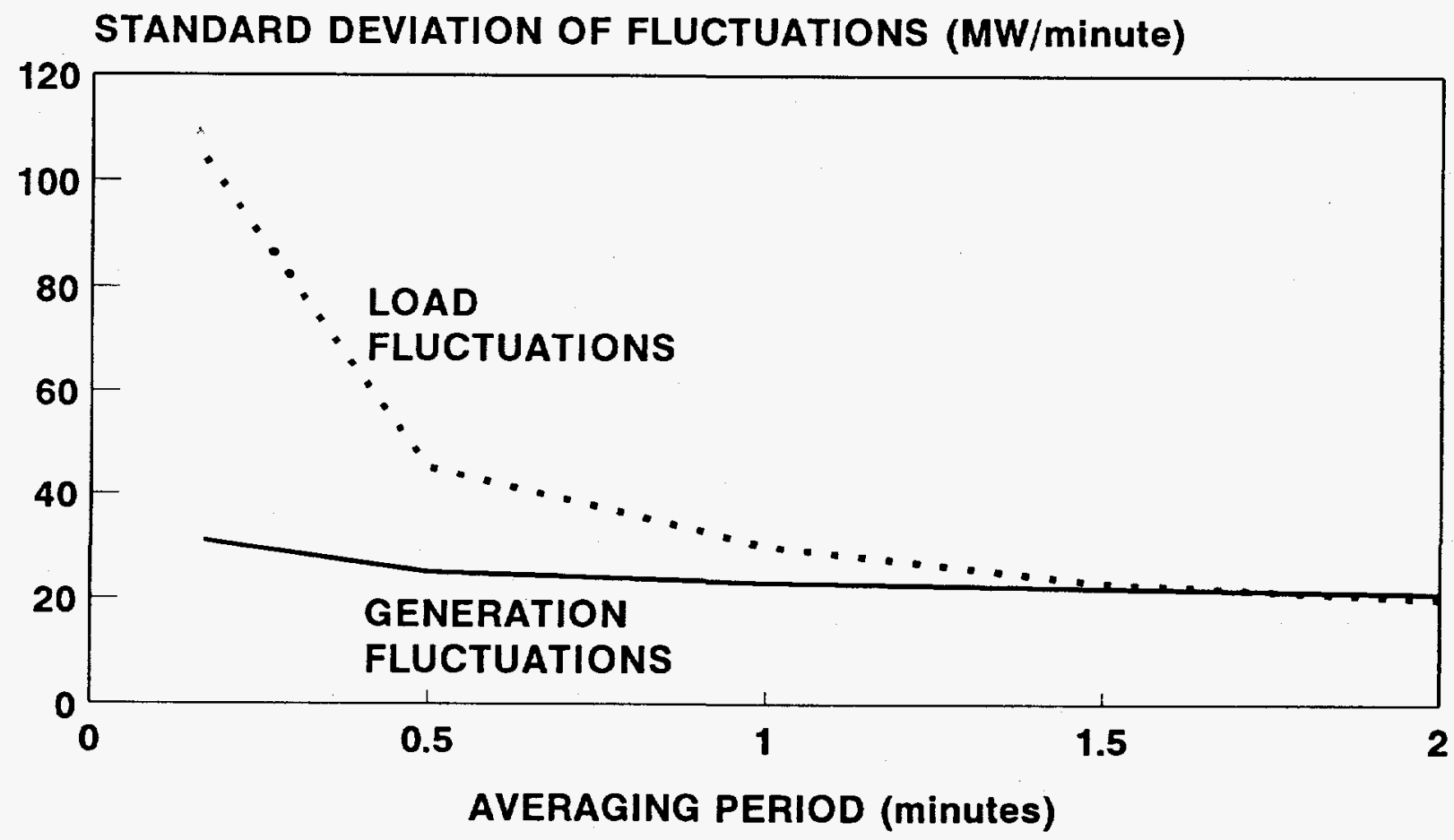

Fig. 7. Standard deviations of load and generator fluctuations for different timeaveraging intervals. 


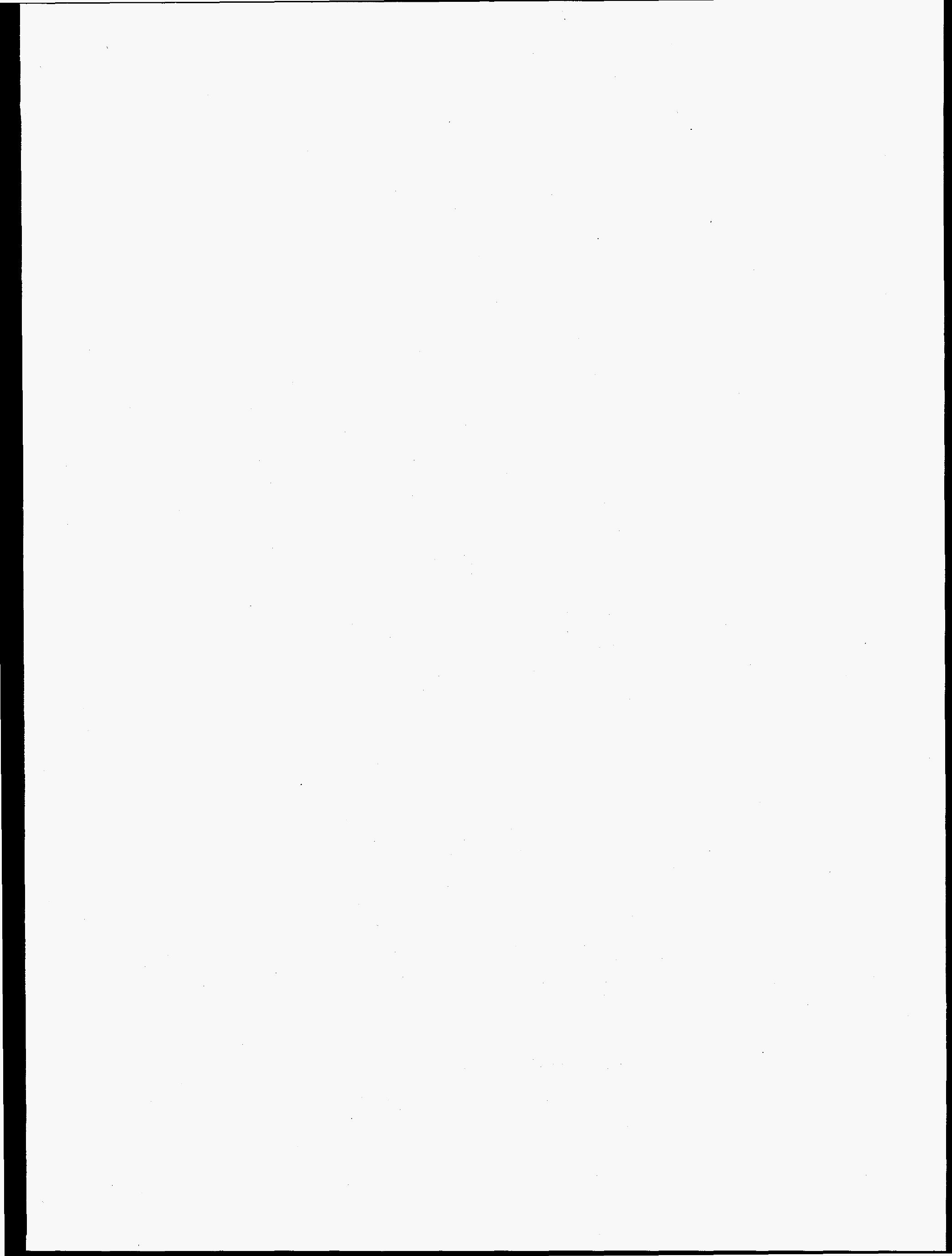

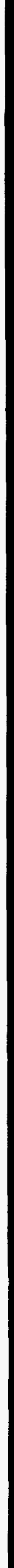




\section{GENERATOR-UNIT RESPONSE TO LOAD FLUCTUATIONS}

The same utility that provided data on 10-second loads and aggregate generation for a day in December 1995 also provided data on the outputs of the individual generating units on regulation. These regulating-unit data are for a 24-hour period in June 1996. We aggregated these data from the 10-second level to 1-minute averages. For the 4-hour period from 10 a.m. to 2 p.m., the 10 units on regulation had an average output of $2800 \mathrm{MW}, 21 \%$ of total generator output during that time. The standard deviation of the output from these 10 units was $800 \mathrm{MW}$, compared with $450 \mathrm{MW}$ for the remaining units. The ratio of standard deviation to mean (coefficient of variation, COV) for the regulating units was $28 \%$, compared with $4 \%$ for the nonregulating units. These statistics show that the output from the regulating units varied much more than that from the nonregulating units, as expected.

During any given period, some of the regulating units were moving in one direction, and other units were moving in the opposite direction. Between 10 a.m. and 2 p.m., regulation in the "primary" direction averaged 12.0 MW/minute, while regulation in the "counter" direction averaged $2.1 \mathrm{MW} /$ minute. This counterregulation averaged $19 \%$ of the primary regulation during this 4-hour period. ${ }^{*}$ Figure 8 displays this phenomenon from 10 to 11 a.m.

Several factors explain this counterregulation (Hoffman 1996):

- The AGC signals from the control center to each generator are unit-specific and reflect that unit's regulating range, ramp rate, and turnaround time (the amount of time it takes the unit to change direction). Thus, the control center might ask fast-response units to change direction, while allowing slow-response units to continue ramping in the original direction.

- The control signals are based on both historical ACE values and on near-term (5 to 15 minute) forecasts of loads, which will modulate the signals sent to individual units. For example, if the forecast shows increasing loads over the next 15 minutes (a reflection of interhour load changes), then a small drop in loads (the intrahour fluctuations) may not necessarily result in a reduction in the output from regulating units.

* In addition, the nonregulating units moved counter to the direction of the regulating units almost $50 \%$ of the time (based on 1-minute averages). During these times, the nonregulating units increased the regulating burden by $28 \%$, measured in $\mathrm{MW} /$ minute. When the two sets of units were moving in the same direction ( $51 \%$ of the time), the nonregulating units contributed an extra $36 \%$ to the regulating units. Thus, these units often added to the regulating burden faced by the utility. 


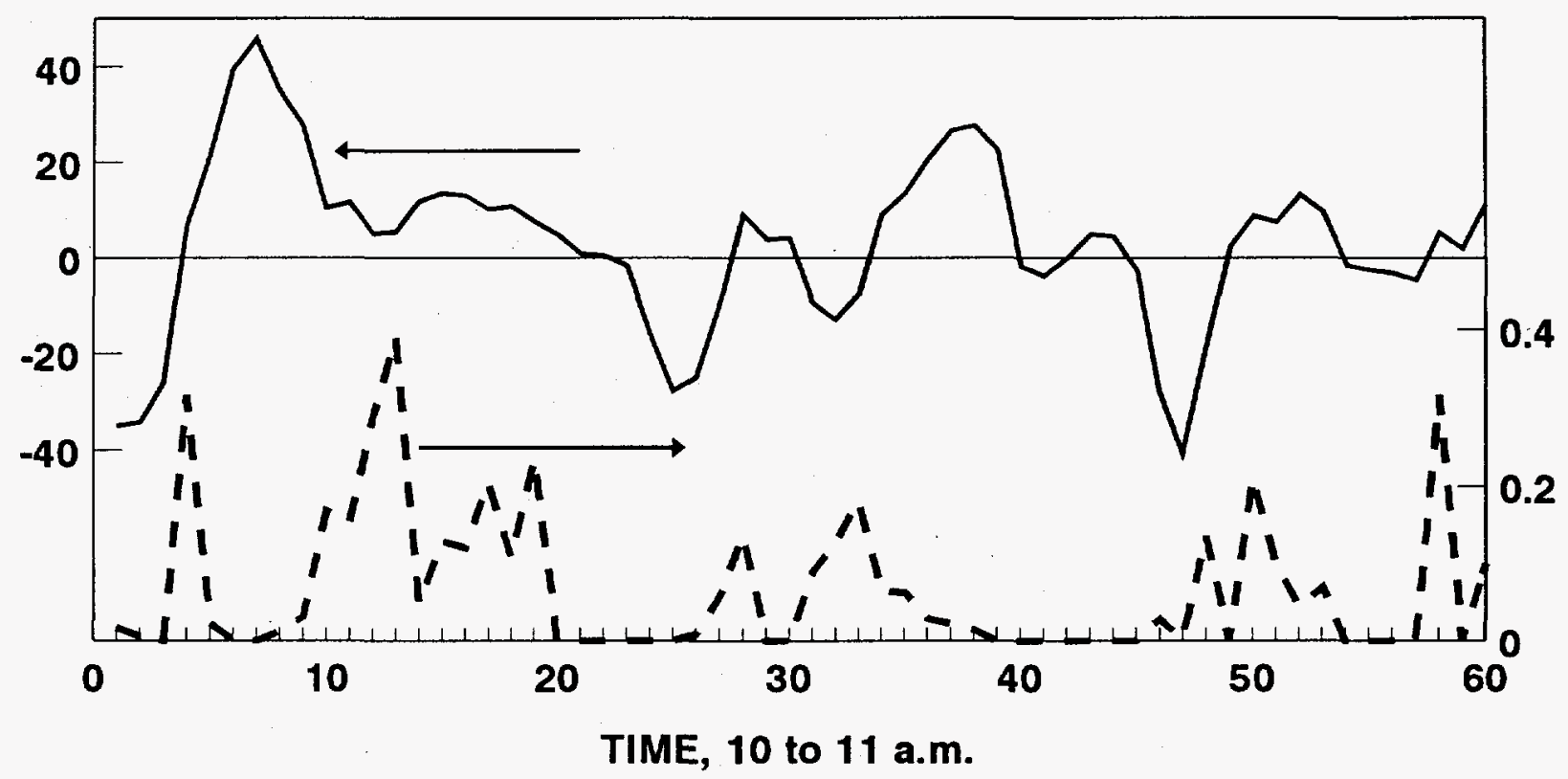

Fig. 8. Changes in output for the 10 units on regulation from 10 to 11 a.m. The solid line shows the net change in generator output, and the dashed line shows the fraction of output that is moving in the counter direction.

- The Al criterion requires the control area to achieve an instantaneous power balance at least once every ten minutes. Meeting this criterion can force AGC to cycle rapidly, always ramping some units up or down. Because of differences in the speed with which individual units can respond, such AGC signals can create situations in which units are not operating in unison.

- Previous AGC signals may have moved some units away from the midpoint of their operating ranges or may have moved units out of economic order. Thus, the signals to some units may be moving these units back while using others to perform the regulating function at certain times.

- Errors in the communications and control systems can cause generators to respond inappropriately (e.g., with time delays or even in the wrong direction) to AGC signals.

Because of these factors, at any given time, some generating units are providing regulation service, and other units are consuming regulation service. That is, some units should receive payments for the regulation service they provide to the system and some units should be charged for the regulation burden they impose on the system. The Bonneville Power Administration (1996) implicitly recognizes these competing roles of generation in its wholesale 
rates. Bonneville maintains $280 \mathrm{MW}$ (about $3 \%$ of its $9000 \mathrm{MW}$ of generation) for regulation. Of this total, $90 \%$ is used to control for variations in load, and $10 \%$ for generator variations.

A utility's ability to follow rapid load fluctuations depends on the mix of generation online and on AGC. The individual units on regulation move up and down with various speeds. Hydro units can respond at 50 to $100 \%$ of their output per minute, combustion turbines at 10 to $20 \%$ per minute, and coal units at 1 to $3 \%$ per minute. Nuclear units are generally not used for regulation. Figures 9 and 10 show the minute-to-minute changes for two units on regulation. Figure 9 shows a unit that followed closely the control-center's AGC signals, with a ramp rate that reached $2 \%$ /minute (positive at 6 minutes and negative at 11 and 12 minutes). Figure 10 shows a unit that responded poorly to the AGC signals, at one point increasing ACE by $31 \mathrm{MW}$.

To illustrate differences between regulating and load-following units, Fig. 11 shows the hourly outputs of two gas/oil units from another utility for a 4-day period. (Ideally, we should show the minute-to-minute output of these two plants to provide a better comparison with Fig. 9; unfortunately such detail was not available.) The maximum ramp rates for these units are about $50 \%$ per hour (110 MW/hour for the 210-MW unit and $80 \mathrm{MW} /$ hour for the $165-\mathrm{MW}$ unit). Comparing Figs. 9 and 11 shows that regulating units move much more rapidly than do nonregulating units $(2 \%$ /minute vs less than $1 \% /$ minute) but over a smaller range (roughly $10 \%$ vs $75 \%$ of unit capacity).

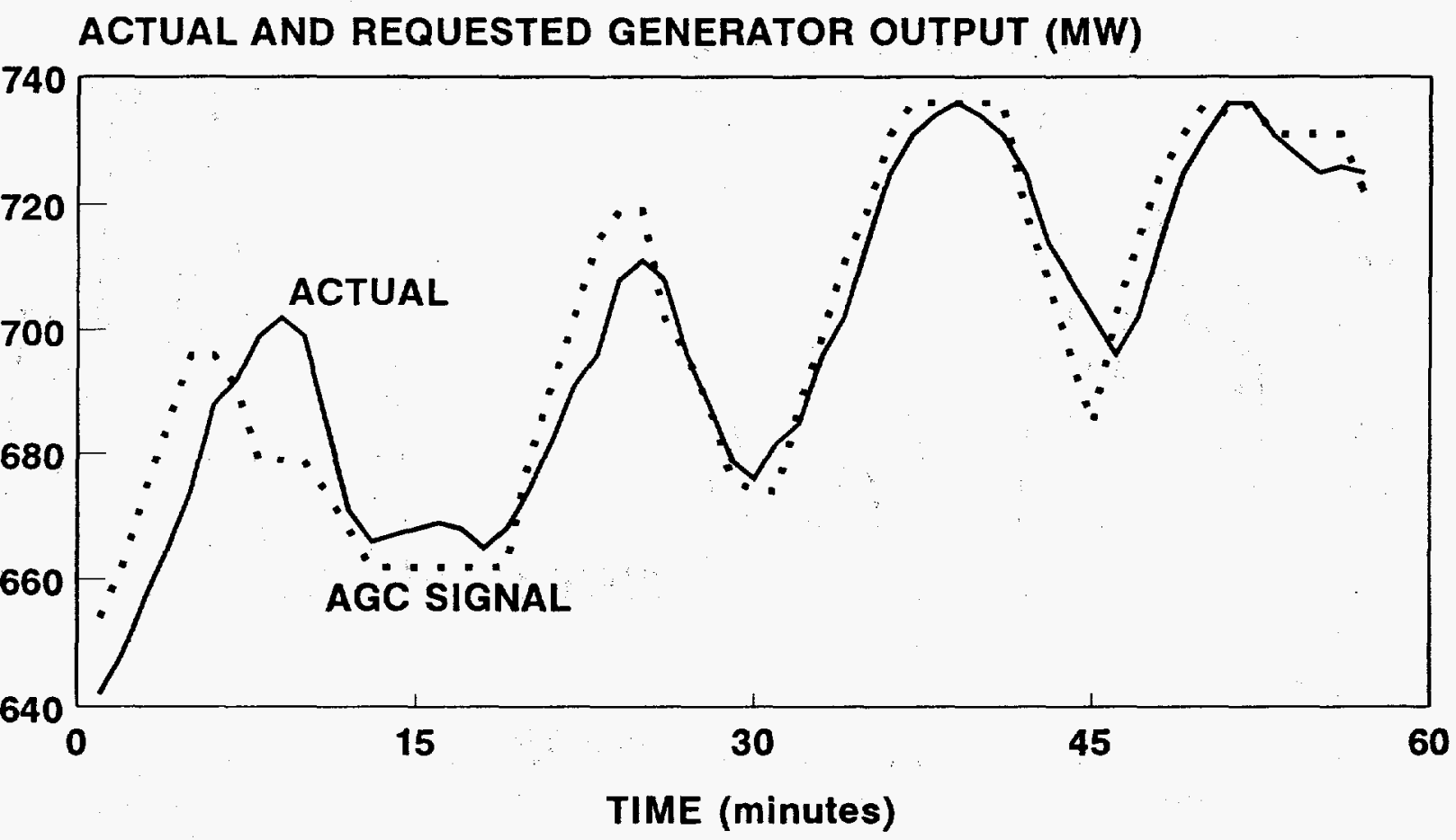

Fig. 9. The minute-to-minute output from a generator providing regulation service. 


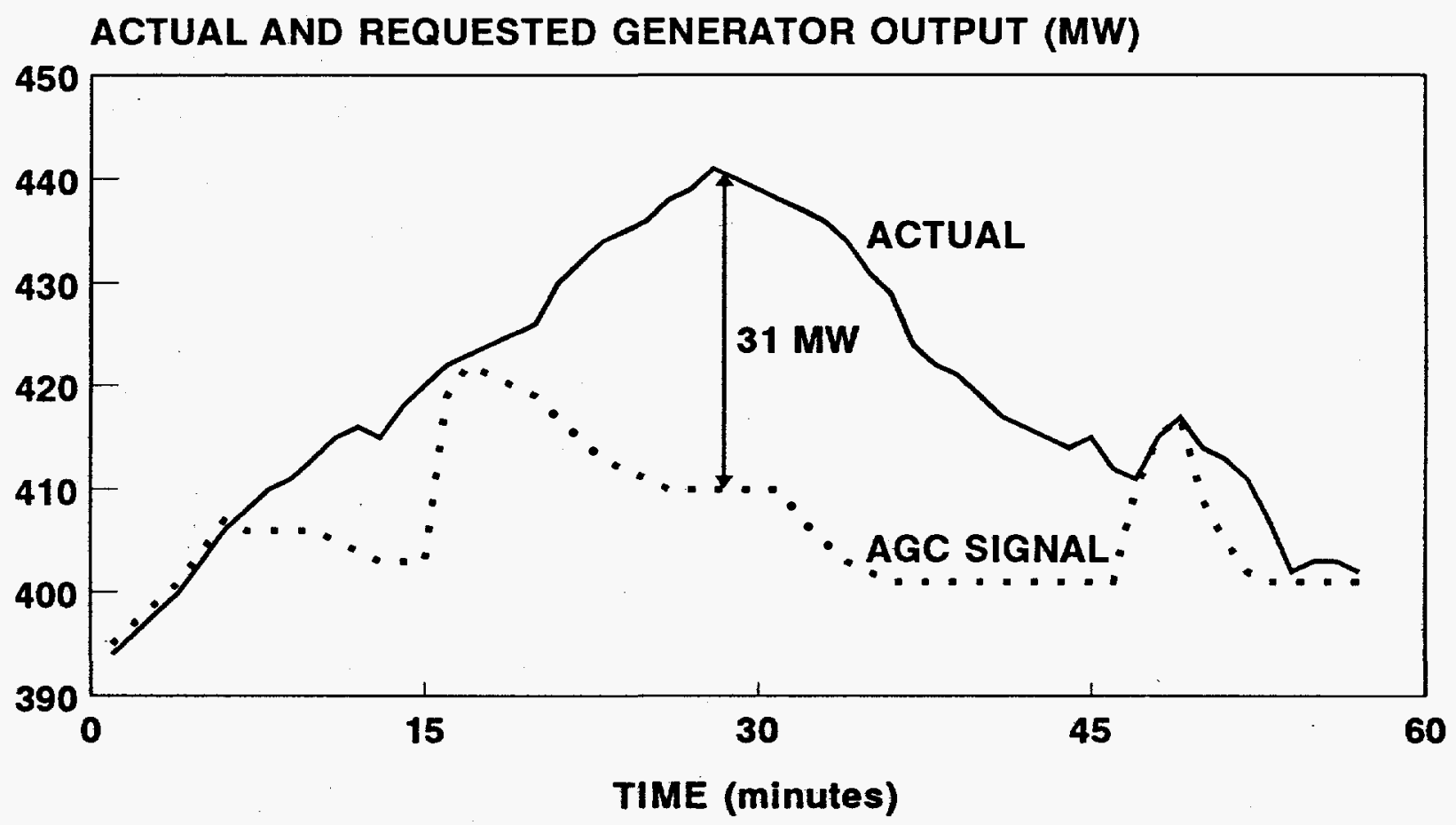

Fig. 10. The minute-to-minute output from a generator providing regulation service, but doing so poorly.

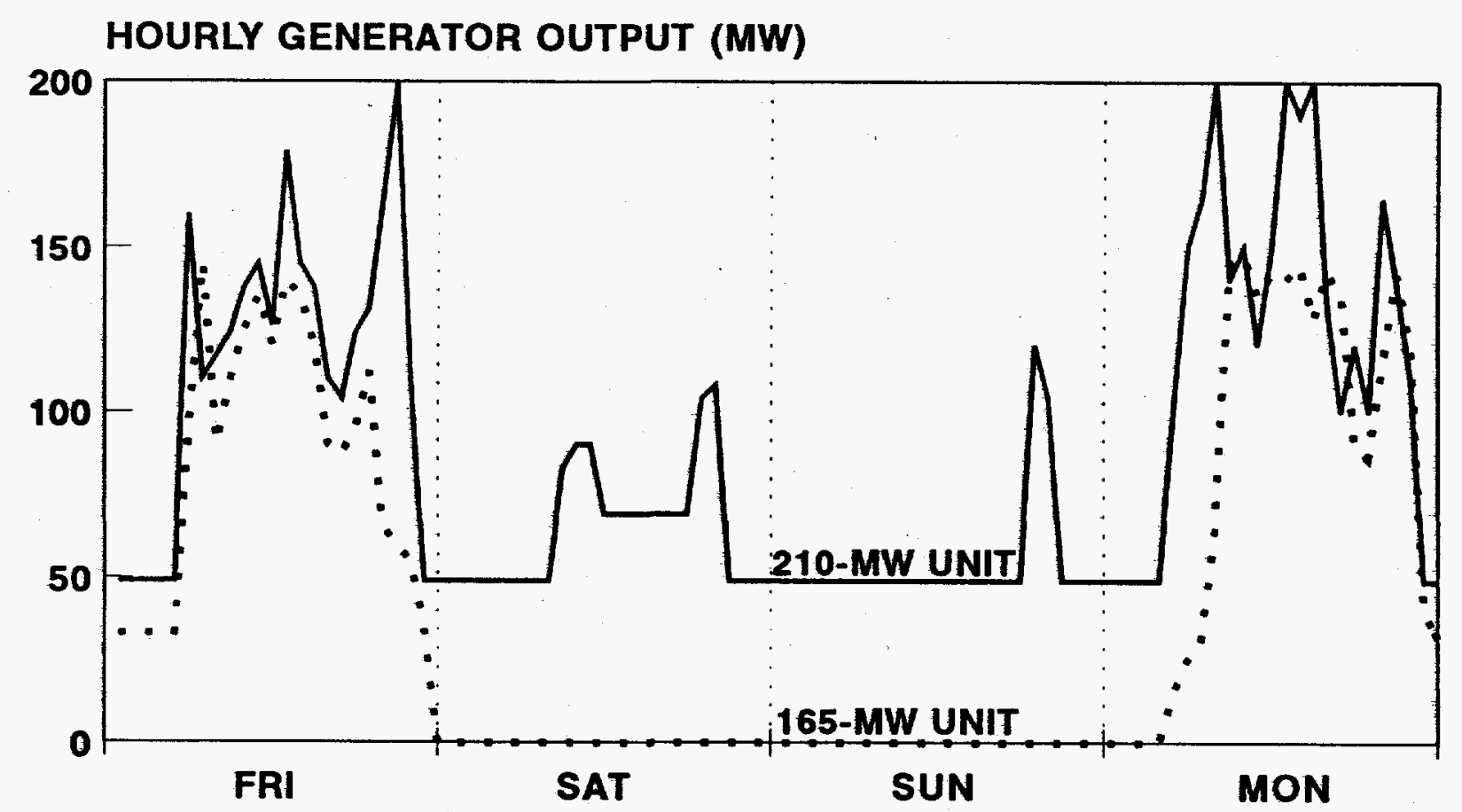

Fig. 11. Hourly outputs from two load-following gas/oil generators operated by a western utility. 


\section{EFFECTS OF INDIVIDUAL LOADS ON TOTAL LOAD SWINGS}

In response to FERC's order to unbundle generation from transmission, utilities and their customers may want to provide and pay for services on a customer-specific basis. This chapter examines the load-following requirements of an individual customer relative to that of the system as a whole.

We assume that the generator cost of load following is proportional to the standard deviation of the aggregate load. The actual amount of generating capacity dedicated to load following will depend on how often the utility is willing to be out of balance with the rest of the interconnection or to allow frequency to deviate from its $60-\mathrm{Hz}$ reference to help provide load following. As we have seen, utilities do not (and as a practical matter can not) compensate completely for load fluctuations.

Consider a group of $\mathrm{N}$ identical customer loads, each of which has a mean of $\mu$ and a standard deviation of $\sigma$. If the customer loads are identical and completely correlated with each other, then the total load has a mean of $\mathrm{N} \mu$ and a standard deviation of No. In other words, the $\mathrm{COV}$ for the entire system is the same as that for each individual load. (The COV is the ratio of the standard deviation to the mean, $\sigma / \mu$.)

Assuming that the loads are perfectly correlated with each other over the short time intervals examined here is quite unrealistic. A much more likely situation is one in which the customer loads are not correlated with each other. ${ }^{*}$ In this case, the total load has a mean of $\mathrm{N} \times \mu$ and a standard deviation of $\sqrt{\Sigma} \sigma^{2}$; that is, $\sigma \times \sqrt{\mathrm{N}}$. Thus, although the total load increases linearly with the number of loads, the load-following requirement for uncorrelated loads increases more slowly, with the square root of the number of loads. Thus, load following shows economies of scale.

The utility might reasonably charge all $\mathrm{N}$ identical customers the same amount for load following. The cost to an individual customer $\mathrm{i}$ for load following is then proportional to $\sigma / \sqrt{\mathrm{N}}$. The marginal impact of each new load, however, decreases as $\mathrm{N}$ rises:

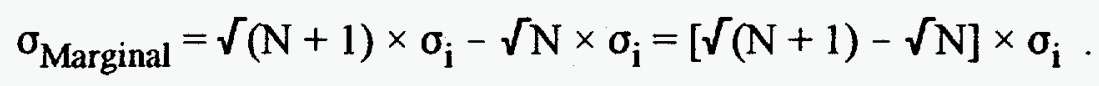

* Loads are correlated with each other over longer time periods, such as from one hour to the next, because of their dependence on common factors, such as the hour of the day, outdoor temperature and humidity, and daylight. Here we assume that the loads are uncorrelated over periods ranging from a few seconds to several minutes. 
Thus, the average load-following cost per customer decreases as the number of customers increases. To the extent that load-following costs are substantial, this characteristic provides a competitive advantage to larger utilities and an incentive for small control areas to combine into fewer, larger ones. From the point of view of customers, load following is one service that is cheaper to provide (per unit of energy or power sold) to small customers than to large customers because there are more small customers for a given utility size. (This statement assumes that the small and large loads have the same COVs.)

The situation is more complicated if the $\mathrm{N}$ independent loads differ in their means and standard deviations. In this case, the load-following requirement for the system is proportional to the standard deviation of the aggregated system:

$$
\sigma_{\text {Total Load }}=\sqrt{\Sigma \sigma_{i}}{ }^{2},
$$

where $\mathrm{i}$ includes all customers. Assigning load-following responsibility to each customer is more complicated as well. One reasonable approach would again look at the marginal contribution of each customer to the total load-following requirement:

$$
\sigma_{\text {Marginal } j}=\sqrt{\Sigma \sigma^{2}}-\sqrt{\left(\Sigma \sigma^{2}-\sigma_{j}^{2}\right)},
$$

where $\mathrm{j}$ is the customer whose load-following requirement is being computed. Because the system is nonlinear, responsibility must be assigned to each load based on its marginal contribution relative to the marginal contributions of all loads:

$$
\sigma_{\text {Marginal j }} / \Sigma \sigma_{\text {Marginal }}=\left[\sqrt{\Sigma} \sigma^{2}-\sqrt{\left.\left(\Sigma \sigma^{2}-\sigma_{j}^{2}\right)\right] / \Sigma_{k}\left[\sqrt{\Sigma} \sigma^{2}-\sqrt{ }\left(\Sigma \sigma^{2}-\sigma_{k}{ }^{2}\right)\right],}\right.
$$

where $\mathrm{k}$ includes all customers. Unfortunately, implementing this method requires knowledge of the standard deviation of each load rather than just those for the total load and the new load of interest.

The preceding examples assumed that the individual loads were uncorrelated with each other. Now we relax that assumption and consider a more complicated situation. We created a hypothetical new load to see how it interacts with the base load to affect overall load fluctuations. This new load consists of three components: (1) a base load equal to a set fraction of the mean of the system load (e.g., 0.01 or 0.05 ), (2) a random component, and (3) a component proportional to the time-varying fluctuations of the system load. Modifying the three parameters that affect these components changes the ways in which this new load interacts with the system load.

and

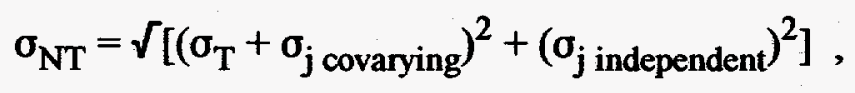

$$
\mu_{\mathrm{NT}}=\mu_{\mathrm{T}}+\mu_{\mathrm{j}} \text {. }
$$

NT refers to the new total system load, and T refers to the original system load (without load j). 
Assuming, as above, that the standard deviation of the total load is the key determinant of load-following requirements, we chose the following metric to measure the change in loadfollowing requirement caused by the addition of a new load:

$$
\left(\sigma_{\mathrm{NT}^{\prime}} / \mu_{\mathrm{NT}}\right) /\left(\sigma_{\mathrm{T}} / \mu_{\mathrm{T}}\right) .
$$

In both numerator and denominator, $\sigma$ is based on fluctuations around the underlying trend. When the above ratio is 1.0 , the new load increases the total load's fluctuations proportional to the increase in total load. In such a case, there is no relative increase in load-following requirement for the overall system, though the contribution of each individual load changes.

Figure 12 shows how changes in the size and standard deviation of the new load affect its contribution to the total load-following requirement. The effect is directly proportional to the square of the size of the load: a new load that is $5 \%$ of the system load, for each value of its $\mathrm{COV}$, adds 25 times as much load-following requirement as does a new load that is only $1 \%$ of the system load. At low values of the new load's COV, its contribution to load following would be less than proportional to its magnitude (e.g., peak MW). For a new load that is $5 \%$ of the system, its load-following burden per MW is higher than for the system as a whole only when its standard deviation exceeds $5 \%$ of its mean. By comparison, the COV of the system load is $0.9 \%$, confirming the less-than-proportional effect of adding a new load identified above.

If the new load is positively correlated with the system load, its contribution to the loadfollowing requirement is higher for all values of its COV than if there were no correlation (Fig. 13). Conversely (and symmetrically), if the new load is negatively correlated with the system load, its contribution to the load-following requirement will be lower.

In summary, a new load can either reduce or increase the total load-following requirement, depending on its size, its volatility, and its correlation with the total load. The larger the new load, the greater its volatility, and the more positively it is correlated with system load, the more it contributes to fluctuations of the total load.

Generation can be treated the same as load in terms of time-varying fluctuations. Generation fluctuations that are positively correlated with load fluctuations are providing regulation and should be compensated for that service. Generation fluctuations that are negatively correlated with load fluctuations increase the load-following burden on the control area and should be charged accordingly. Thus, while it might make sense to pay generators for making their units available to the system operator (a reservation charge), it may be more important to pay (or charge) generators for real-time performance. 
LOAD-FOLLOWING BURDEN RELATIVE TO SIZE OF NEW LOAD

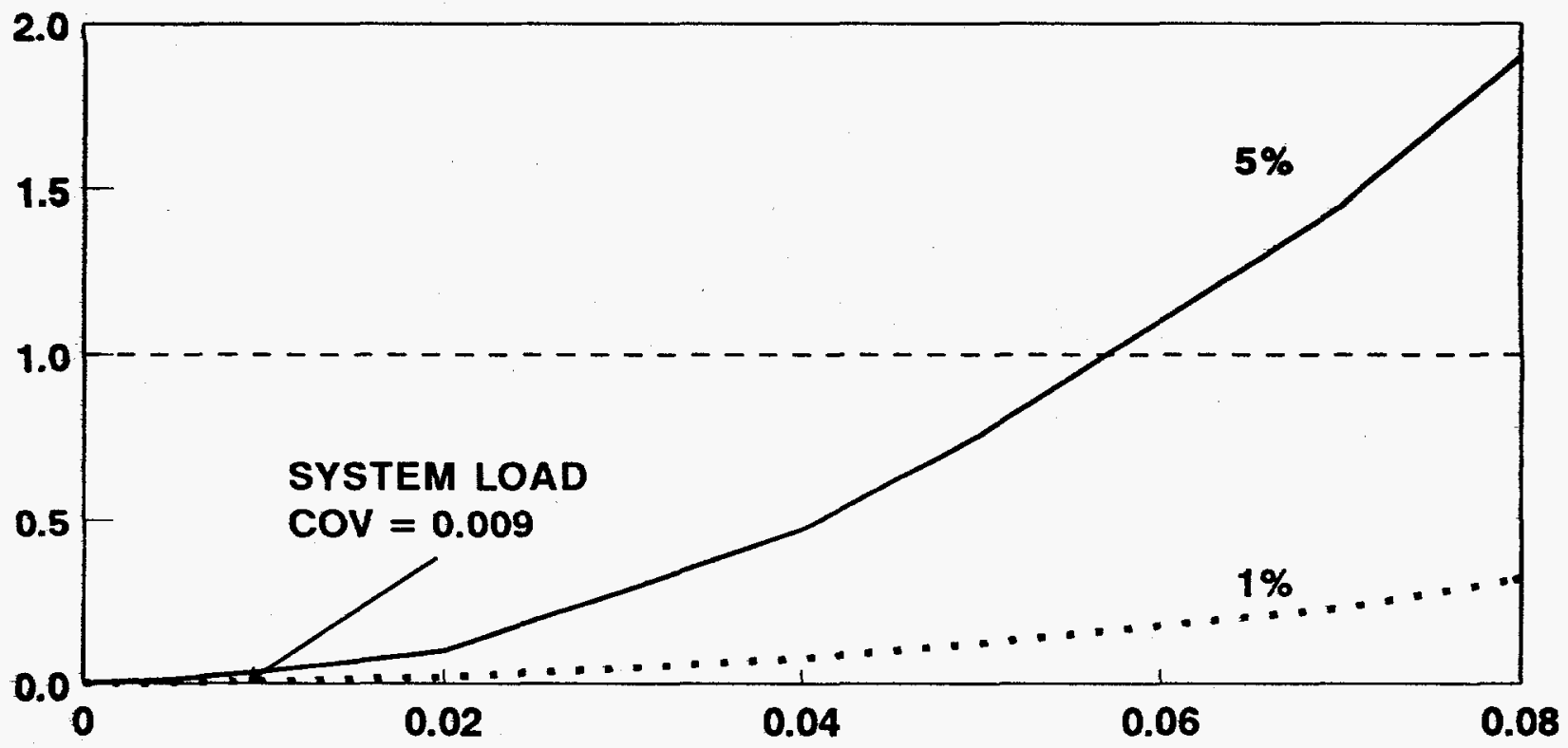

STANDARD DEVIATION/MEAN OF NEW LOAD (COV)

Fig. 12. The relative contribution of a load to the total load-following requirement as a function of the load's magnitude and standard deviation.

LOAD-FOLLOWING BURDEN RELATIVE TO SIZE OF NEW LOAD

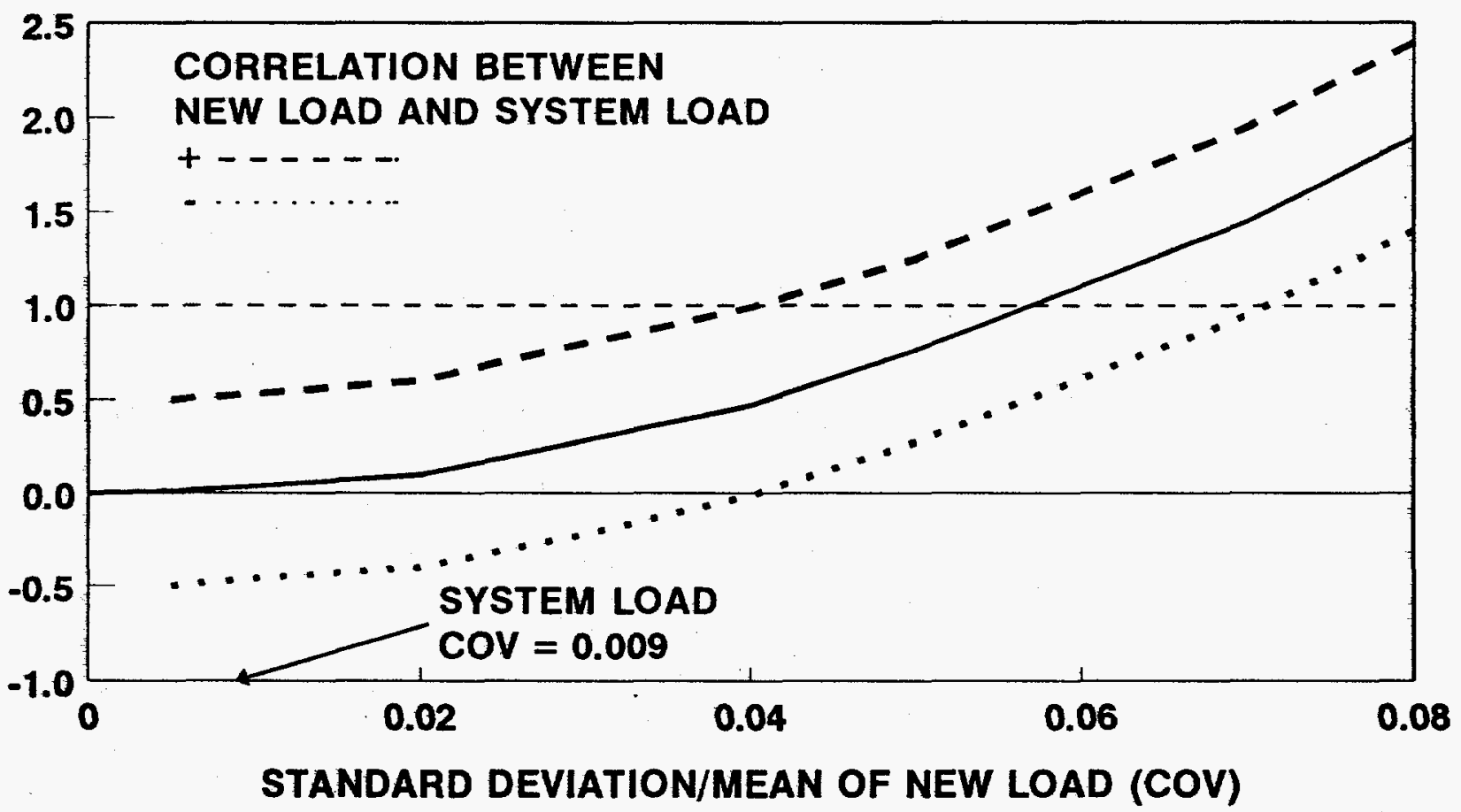

Fig. 13. The relative contribution of a new to the total load-following requirement as a function of the load's standard deviation and correlation with the system load. The load is $5 \%$ of the system load. 


\section{CONCLUSIONS}

\section{SUMMARY}

Using data on loads and generation from a large Midwestern control area, we examined several characteristics of load following. First, we used various averaging methods (i.e., rolling averages and regression models) to identify and define the interhour trends in system load. We found that a simple cubic fit to several hours of 1-minute load data yields satisfactory definitions of inter- and intrahour dynamics.

Using these averaging methods, we identified the intrahour load fluctuations. We compared the characteristics of inter- vs intrahour load. The short-term fluctuations differ from the long-term load changes in three ways. First, the magnitude (MW) of interhour load changes is much greater than that of intrahour load fluctuations. Second, the intrahour fluctuations change much more rapidly (MW/minute). And third, the intrahour fluctuations change direction much more often than do the interhour load changes.

Next, we examined intrahour load swings in detail, focusing on the magnitude of load swings (measured by the maximum load change, standard deviation, and average of absolute value) and the rate of change of load swings (measured by the average of absolute value of load change and the number of sign changes per hour). We analyzed the implications of alternative time-averaging periods, ranging from 10 seconds to 2 minutes. While the standard deviation and average of absolute values of the magnitude are nearly invariant with the time-averaging period, the measures of rate of change are very sensitive to the averaging period.

Then we examined the response of generators, in aggregate and individually, to these moment-to-moment load fluctuations. Comparing the dynamics of load and generator fluctuations shows that the generators follow load fluctuations at roughly the 1- to 2-minute level; that is, generators either cannot or do not follow higher-frequency load fluctuations. We also saw that many generating units, both some of those assigned to regulation and others not on regulation, contribute to the regulating burden that the utility faces. For example, during one 4-hour period, the units moving in the "primary" direction followed load with an average movement of $12.0 \mathrm{MW} /$ minute. At the same time, regulating units moving in the "counter" direction averaged $2.1 \mathrm{MW} /$ minute in the wrong direction. We suggest calling the response of generators to short-term (less than 10 minutes) load fluctuations "regulation;" we suggest calling the response of generators to longer-term (more than 10 minutes) load variations "load following." 
Finally, we developed a simple analytical model to show how system load fluctuations depend on the contributions of individual loads and their fluctuations. For uncorrelated loads, the average load-following burden per customer decreases as the number of customers increases.

\section{ISSUES TO RESOLVE}

The present analysis leads to the following thoughts on issues that require further data and analysis. Additional research is required, we believe, because the results presented here are based on very limited data, primarily from one utility for only a day or two.

- What methods should be used to identify and define the hour-to-hour trends in system load (load following)? What criteria should be used in selecting a preferred method?

- What are the appropriate metrics to use in defining intrahour load following? Are the characteristics considered here - the magnitude of load changes (MW), the speed of load changes (MW/minute), and the number of direction changes-appropriate and sufficient? The metrics chosen must be practical, both for metering and billing purposes.

- What is the relationship between the amount and speed of generating capacity assigned to regulation and the magnitude and speed of intrahour load changes? For this control area, the amount of generating capacity assigned to regulation $(150 \mathrm{MW})$ is 2.3 times the standard deviation of load changes (66 MW, Table 3). How does this "proportionality constant" vary by day of the week and season for this control area, and how does it vary across control areas?

- What is the appropriate period over which to measure regulation requirements? Although utility automatic-generation-control systems typically obtain data at 2-second intervals, this is surely not the appropriate time period. Based on our comparison of the speed with which generators and loads vary, we suggest that a 1-or 2-minute averaging period should be used to measure the magnitude and speed of load changes.

- How accurately and rapidly do (and must) individual generating units follow the AGC signals that the control center sends them? To what extent are some units moving counter to the direction that the AGC signals request? Is the amount of regulation that utilities currently provide appropriate? What effects would changes in the amount of regulation have on customer service, reliability, and cost?

- How should the charges for load following reilect the characteristics of individual loads vs those of the system load? Because of economies of scale, load following is normally provided for the aggregated system load, not for individual loads. Methods to cost and price load following for individual customers should recognize the nonlinearities in the interactions among individual loads to create the system load. Because the standard 
deviation of the aggregated load is equal to the square root of the sum of the squares of the standard deviations of the individual, uncorrelated loads, small loads impose a disproportionately low load-following burden on the system. How should generators be compensated for their contributions to regulation and load following? How should generators that add to the load-following burden (rather than meet that burden) be charged for their contribution to the control-area's regulating requirement?

\section{ACKNOWLEDGMENTS}

We thank John Ballance, Albert DiCaprio, Fred Duckett, Lester Fink, Stephen Hoffman, Charles Hudson, Eric Mscichowski, Steven Naumann, Antonio Sammut, Henry Schwab, Jerry Smith, Clyde Stansberry, Peter Steitz, John Stout, Raymond Vice, and Steven Walton for their helpful comments on a draft of this report. We thank Stephen Hoffman and Howard Illian for their help in obtaining and interpreting data. We thank Fred O'Hara for editing this report and Ethel Schorn for managing its clearance, printing, and distribution. 



\section{REFERENCES}

D. Benjamin 1996, Interconnected Operations Services: A Technical Discussion, draft, North American Electric Reliability Council, Princeton, NJ, July.

Bonneville Power Administration 1996, Wholesale Power Rate Development Study, WP-96-FSBPA-05, Portland, OR, June.

L. D. Douglas, T. A. Green, and R. A. Kramer 1994, "New Approaches to the AGC NonConforming Load Problem," IEEE Transactions on Power Systems 9(2), 619-628, May.

L. H. Fink and I. Erkmen 1987, "Economic Dispatch to Match Actual Data to the Actual Problem," Proceedings: 1986 Power Plant Performance Monitoring and System Dispatch Conference, EPRI CS/EL-5251-SR, Electric Power Research Institute, Palo Alto, CA, July.

E. Hirst and B. Kirby 1996, Electric-Power Ancillary Services, ORNL/CON-426, Oak Ridge National Laboratory, Oak Ridge, TN, February.

S. Hoffman 1996, personal communication, Bulk Power Operations, Commonwealth Edison, Lombard, IL, July.

N. Jaleeli, L. S. VanSlyck, D. N. Ewart, L. H. Fink, and A. G. Hoffman 1992, "Understanding Automatic Generation Control," IEEE Transactions on Power Systems 7(3), 1106-1122, August.

B. Kirby and E. Hirst 1996, Ancillary Service Costs for 12 U.S. Electric Utilities, ORNL/CON427, Oak Ridge National Laboratory, Oak Ridge, TN, March.

North American Electric Reliability Council 1992, Control Area Concepts and Obligations, Princeton, NJ, July.

North American Electric Reliability Council 1996, Interconnected Operations (Ancillary) Services: Workshop on Definitions and Requirements for Managing Unbundled IOS, Princeton, NJ, June 19-20.

Pacific Gas and Electric, San Diego Gas and Electric, and Southern California Edison 1996, Joint Application for Authorization to Convey Operational Control of Designated Jurisdictional 
Facilities to an Independent System Operator, Docket No. EL96-48-000, before the Federal Energy Regulatory Commission, San Francisco, San Diego, and Rosemead, CA, April 29.

Pacific Gas and Electric Company 1996, "Capacity Requirements for Load Following Ancillary Services," Order 888 Compliance Filing, before the Federal Energy Regulatory Commission, San Francisco, CA, July 8.

PJM Interconnection Association 1996, Restructuring of the Pennsylvania-New JerseyMaryland Interconnection, before the Federal Energy Regulatory Commission, Norristown, PA, July 24 .

A. Sammut 1996, "Regulation," Interconnected Operations (Ancillary) Services: Workshop on Definitions and Requirements for Managing Unbundled IOS, Palm Beach Gardens, FL, June 19-20.

P. Steitz 1996, "Load Following," Interconnected Operations (Ancillary) Services: Workshop on Definitions and Requirements for Managing Unbundled IOS, Palm Beach Gardens, FL, June 19-20.

U.S. Federal Energy Regulatory Commission 1996, Promoting Wholesale Competition Through Open Access Non-Discriminatory Transmission Services by Public Utilities; Recovery of Stranded Costs by Public Utilities and Transmitting Utilities, Final Rule, Docket Nos. RM95-8000 and RM94-7-001, Order 888, Washington, DC, April 24. 
INTERNAL DISTRIBUTION

1. D. Bauer

2. L. Baxter

3. V. D. Baxter

4. L. Berry

5. D. S. Bjornstad

6. M. A. Brown

7. J. Christian

8. G. Courville

9. T. R. Curlee

10. P. D. Fairchild

11. S. Hadley

12. L. J. Hill

13. E. Hirst

14. P. J. Hughes

15. B. Kirby

16. R. Lee

17. P. Leiby
18. J. M. MacDonald

19. V. C. Mei

20. D. E. Reichle

21. A. C. Schaffhauser

22. M. Schweitzer

23. R. B. Shelton

24. J. Tomlinson

25. B. E. Tonn

26. J. Van Dyke

27. J. VanCoevering

28. T. J. Wilbanks

29. ORNL Patent Office

30. Central Research Office

31. Document Reference Section

32. Laboratory Records (RC)

33-35. Laboratory Records Dept.

\section{EXTERNAL DISTRIBUTION}

40. Dr. Thomas E. Drabek, Professor, Department of Sociology, University of Denver, Denver, CO 80208-0209

41. Dr. Stephen G. Hildebrand, Director, Environmental Sciences Division, Oak Ridge National Laboratory, P.O. Box 2008, Oak Ridge, TN 37831-6037

42. Mr. George F. Sowers, P. E., Senior Vice President, Law Companies Group, Inc., 114 Townpark Drive, Suite 250, Kennesaw, GA 30144-5599

43. Dr. C. Michael Walton, Ernest H. Cockrell Centennial Chair in Engineering and Chairman, Department of Civil Engineering, University of Texas at Austin, Austin, TX 78712-1076

44.-46. OSTI, U.S. Department of Energy, P.O. Box 62, Oak Ridge, TN 37831

47. Office of Assistant Manager for Energy Research and Development, DOE/ORO, P.O. Box 2001, Oak Ridgè, TN 37831-8600

48.-700 External Electric Industry Policy Studies group distribution mailing list and extra copies to E. M. Schorn, $4500 \mathrm{~N}, \mathrm{H}-19 \mathrm{~A}$ 